\title{
What Makes a 'Community Informant'? Reliability and Anti-predator Signal Eavesdropping Across Mixed-Species Flocks of Tits
}

\author{
Nora V. Carlson ${ }^{1 *}$, Susan D. Healy ${ }^{2}$, and Christopher N. Templeton ${ }^{2,3^{*}}$ \\ ${ }^{1}$ Department of Collective Behavior, Max Planck Institute of Animal Behavior, Germany \\ ${ }^{2}$ School of Biology, University of St. Andrews, Scotland \\ ${ }^{3}$ Department of Biology, Pacific University, USA \\ *Corresponding author (Email: Nora.v.carlson@gmail.com, templeton@pacificu.edu)
}

Citation - Carlson, N. V., Healy, S. D., \& Templeton, C. N. (2020). What makes a 'community informant'? Reliability and anti-predator signal eavesdropping across mixed-species flocks of tits. Animal Behavior and Cognition, 7(2), 214-246. doi: https://doi.org/10.26451/abc.07.02.13.2020

\begin{abstract}
Mobbing is an anti-predator behavior where multiple species collectively harass a predator while vocalizing. These flocks are made up of species whose vocalizations contain information about predator threat (information sources), and those that eavesdrop on this information (scroungers). To be a community informant (a key information source), a species needs to meet two criteria: (1) the detailed predator threat information they produce must be consistently reliable across mobbing events, and (2) this information must be used by eavesdropping species. As tits (Paridae) have traditionally been assumed to be community informants, we tested whether they meet these criteria. Specifically, we used field experiments with predator mounts to: (1) test the reliability of the encoded information across mobbing events with different community compositions (different species present), and (2) examine the vocal response of previously assumed scrounger species to predators. We found that only blue, great, and coal tits, produced reliable predator threat information regardless of community composition, and each scrounger species acted on the information that tits provided to a different degree. Additionally, we found that both 'scrounger' species produced their own information about predators by varying their own mobbing vocalizations in response to the presence of predators. These results suggest that not all species that produce predator threat information are community informants, not all species that appear to eavesdrop on this information do so to the same degree, and some species that initially appear to be scroungers will actually produce their own information about predator encounters.
\end{abstract}

Keywords - Mixed-species flocks, Mobbing, Community informants, Satellite species, Paridae

Information about predators is vital for the survival of prey, and many species, across a wide range of taxa, produce anti-predator vocalizations that help to defend themselves and others from predators (Gill \& Bierema, 2013; Townsend \& Manser, 2013). These anti-predator signals not only warn about the presence of a predator, but can contain information about the predator's specific level of threat, such as its size (Evans et al., 1993; Templeton et al., 2005), speed (Evans et al., 1993), distance (Baker \& Becker, 2002; Murphy et al., 2013), type (Griesser, 2009; Placer \& Slobodchikoff, 2000, 2004; Suzuki, 2014, 2018), and even behavior (Gill \& Bierema, 2013; Griesser, 2008; Marler, 1955; Townsend \& Manser, 2013). As this information can be costly to acquire and produce, it is thought that many species, instead of acquiring their own information, eavesdrop on other species' anti-predator signals (Clucas et 
al., 2004; Fuong, et al., 2014; Igic et al., 2019; Lea et al., 2008; Magrath \& Bennett, 2012; McLachlan et al., 2019; Munoz et al., 2015; Sherman, 1977; Templeton \& Greene, 2007).

Given the variation in the extent to which species produce information about predators, communities are thought to be made up of information sources, those species that frequently produce reliable and detailed information about predator threats, information scroungers, those species that instead eavesdrop on the information contained in other species' anti-predator signals, and community informants, an information source species whose anti-predator calls are so widely used by heterospecifics in the community that their presence can affect the species dynamics and structure of that community (Goodale \& Beauchamp, 2010; Goodale et al., 2010; Hetrick \& Sieving, 2011; Pagani-Núñez et al., 2018; Soard \& Ritchison, 2009). To be considered a reliable community informant, a species must not only produce detailed predator threat information that is both relevant and easily acquired by other species, it must also be consistent in the ways in which it encodes this information about predators (Goodale \& Ruxton, 2010; Magrath et al., 2009, 2014; McLachlan et al., 2019; Pagani-Núñez et al., 2018; Rieucau \& Giraldeau, 2011; Schmidt et al., 2010). Most important, however, the information they produce must actually be used by other species in the community, specifically many other species must rely on this information (Magrath et al., 2014; Schmidt et al., 2010). To understand how information in these systems actually flows between these categories of individuals, we need to first address three areas: 1) the reliability of information produced by 'community informants,' 2) the use of this information by 'scroungers,' and 3) the reliance of 'scroungers' on the information of 'community informants.'

\section{Reliability of 'Community Informants'}

Because those species assumed to be community informants supply detailed information about predator threat to which both conspecifics and heterospecifics respond (Bartmess-LeVasseur et al., 2010; Carlson et al., 2020; Fuong et al., 2014; Goodale \& Kotagama, 2008; Magrath et al., 2009; Suzuki, 2016; Suzuki \& Kutsukake, 2017; Templeton \& Greene, 2007), it is thought that the information provided is generally reliable across events (Bartmess-LeVasseur et al., 2010; Fuong et al., 2014; Magrath et al., 2009; Templeton \& Greene, 2007). However, in nature, each mobbing event is different (e.g., varying in numbers of individuals, species assemblages including conspecific and heterospecific individuals; Courter \& Ritchison, 2010; Igic et al., 2019; Morse, 1973; Woods et al., 2018), and the relative investment in mobbing by each species, etc. (Nolen \& Lucas, 2009; Randler \& Vollmer, 2013). If community informants are sensitive to these differences, the ways in which they encode predator threat information in their vocalizations could in turn vary with group structure (Townsend et al., 2012).

To be a reliable source of information to heterospecifics (i.e., the community), community informants should produce signals unaffected by variation in flock structure. This is because variability in signalling due to social factors not directly related to the pertinent threat (e.g., flock size or species composition) would be more likely to impact a heterospecific individual's ability to 'decode' information from anti-predator signals because many heterospecifics tend to be only temporary or a peripheral part of the group structure. Being only temporary or peripheral to the community informants' flock may lower a heterospecific's ability to keep track of the subtle details of flock structure necessary to 'decode' calls that integrate this type of information. Similarly, if heterospecifics have less contact with the community informant's flock, they may also be less skilled at extracting nuanced information from the calls (Randler \& Förschler, 2011). Effective community informants should, then, produce signals that are largely unaffected by factors other than the pertinent threat. While this variability has frequently been taken into account, there has been no explicit test of this assumption. More typically, data are averaged across different predator encounters, which, while showing how 'community informants' encode information, does not address the amount or causes of variation (Blumstein \& Armitage, 1997; Carlson, Healy et al., 2017; Courter \& Ritchison, 2010; Welbergen \& Davies, 2008).

There are several potential factors that might lead to variation in signalling behavior; here we focus on three key variables: group size (i.e., combined conspecific and heterospecific number), conspecific number, and presence of heterospecifics. Group size could affect perceived threat by 
changing an individual's probability of being eaten. Individuals in larger groups, for example, may perceive a threat as lower due to selfish herd (Hamilton, 1971) or confusion effects (Blumstein et al., 1999; Caro, 2005; Curio, 1978; Goodale \& Ruxton, 2010) eliciting vocalizations indicating a lower threat than those elicited by the same predator when encountered by a smaller group. The presence of conspecifics can impact alarm calling as well (Fichtel \& Manser, 2010; Townsend et al., 2012). For example, some species of birds (Griesser \& Ekman, 2004, 2005; Karakashian et al., 1988; Marler, 1957; Sullivan, 1985) and mammals (Cheney \& Seyfarth, 1985; Sherman, 1985, Townsend et al., 2012; Wich \& Sterck, 2003) are less likely to call, or to encode detailed information in their calls, unless conspecifics, such as kin or mates, are present. The presence of heterospecifics can also affect the calling behavior of some species, for example, by either not calling or by increasing calling behavior (Griesser \& Ekman, 2005; Igic et al., 2019; Karakashian et al., 1988; Ridley et al., 2007).

\section{Use of Information by 'Scroungers'}

While producing reliable information is one important criterion for identifying community informants, to actually designate a species as such also requires that the information it produces must also be used by heterospecifics in the community. Sympatric nuclear species (Hetrick \& Sieving, 2011) or species that produce detailed predator threat information (Fallow \& Magrath, 2010; Shriner, 1998) will eavesdrop on each other, responding appropriately to the fine-scale predator threat information in each other's anti-predator vocalizations (Fallow \& Magrath, 2010; Hetrick \& Sieving, 2011; Shriner, 1998). However, there has been little examination of whether species thought to be information scroungers respond appropriately to the information produced by community informants (Fuong et al., 2014; Sullivan, 1985, 1994; Suzuki, 2016).

Determining whether a species fits into the role of information scrounger may also be done based on its vocal interactions with a community-informant species. The mobbing calls of many species are similar, both in their broadband quality and frequency ranges (Ficken \& Popp, 1996; Marler, 1957; Randler, 2012), thereby potentially masking one or multiple other species' mobbing calls (Magrath et al., 2014; Wiley, 2009; Zhou et al., 2019). Degradation and attenuation of heterospecific alarm calls can change the response of eavesdroppers to the information contained within those calls, possibly due to poorer detection or recognition of the call (Grade \& Sieving, 2016; Murray \& Magrath, 2015; Templeton et al., 2016; Wiley, 2009; Zhou et al., 2019). As for producer/scrounger dynamics in foraging contexts, information scroungers may not be able to both produce and receive information (in this case auditory; Rieucau \& Giraldeau, 2011), restricting their ability to receive a signal accurately when they are not producing one (Bee \& Micheyl, 2008). To increase accurate reception of and to avoid masking the information contained in the calls produced by community informants, eavesdroppers may avoid calling when community-informant species call (Bee \& Micheyl, 2008) and then appear to 'pay attention' to the calls of community informants.

\section{Reliance on Information by 'Scroungers'}

Additionally, as eavesdropping species are necessarily listening to and using the information provided by community informants, the assumption is that they rely primarily on these calls and likely do not produce any information of their own (Moynihan, 1962; Ridley et al., 2013). If an individual from a satellite species can or does produce information about predator threat in their own calls, then a further assumption is that, when predator threat information is available (i.e., being produced by a communityinformant species), then the 'scrounger' should not encode this information in their calls, thereby lowering their own energy expenditure or risk of attracting attention of a predator (Carlson et al., 2020). This is due to the fact that often species encode increased threat by increasing their call rate or the number of elements in their call (Carlson, Healy et al., 2017; Landsborough et al., 2019; Suzuki, 2014; Templeton et al., 2005), thereby increasing the ease of localizing the calling individual (Krama, 2007; Krams, 2001). Therefore, especially when encountering a dangerous predator, if the information is already available, 
individuals should avoid increasing their conspicuousness to predators and energetic expenditure by not increasing their own calling behavior.

To address whether those species thought to be community informants produce reliable information that is used, and relied upon, by scroungers in their community, we simulated predator encounters to species assumed to be community informants and those assumed to be information scroungers. We treated tits as our community informants because, in addition to chickadees specifically, Paridae in general are often referred to as community informants in the literature (Hetrick \& Sieving, 2011; Lilly et al., 2019; Pagani-Nunez et al., 2018). Parids frequently respond to the presence of predators by engaging in mobbing behavior, and five out of the six UK species encode detailed information about predator threat using at least one encoding method (Carlson, Healy et al., 2017), which suggests they may be important sources of information about predator threat. These species are, then, good candidates to be community informants. We chose European robins, Erithacus rubecula, and dunnocks, Prunella modularis, as our 'scrounging' species as they fit many of the ecological/life history traits that many 'scroungers' are thought to embody (i.e., are not key in recruitment to flocks, are territorial, and live in smaller groups; Moynihan, 1962; Ridley et al., 2013).

To confirm whether birds commonly thought to be community informants based on their ability to encode predator threat information in their mobbing calls actually fulfil this role, we performed predator presentation experiments with high and low threat predators to examine the roles of different species of small songbirds living in mixed-species flocks in Britain. We tested whether 'informant' species produce reliable information about predators, whether that information is readily used by heterospecifics, and, specifically, used by multiple heterospecific species. We examine how social interactions within a community affect information production about predators by testing three predictions based on the areas discussed above: 1) community-informant species should reliably differentiate between predators of different threat levels using vocalizations that are uninfluenced by social factors like flock size (conspecific or heterospecific) or composition, and 2) scroungers in the species community should 'pay attention' to this information by avoiding calling when 'informant' species are calling (i.e., to lower the chance of masking these important calls), and use this information because they do not produce information about predator threat in their own calls (thereby not changing their calling behavior because they cannot vocally differentiate between predators), and 3) multiple 'scrounger' species should 'pay attention' to community-informant species (to be a community informant, the community must use that information, not just one heterospecific).

\section{Method}

\section{Study Sites and Species}

\section{Reliability of Community Informants}

We studied six putative 'community-informant' species from the Paridae; blue tits (Cyanistes caeruleus), great tits (Parus major), coal tits (Periparus ater), crested tits (Lophophanes cristatus), marsh tits (Poecile palustris), and willow tits (Poecile montanus) to see if they did, in fact, act as community informants. Blue, great, and coal tits are found throughout the UK (Perrins et al., 1979). Blue and great tits prefer primarily broad-leaved deciduous woodland whereas coal tits prefer more conifer dense habitats (Perrins et al., 1979). Crested tits are restricted to the northwest of Scotland and prefer new Caledonian or Scots pine forests (Perrins et al., 1979). Marsh and willow tits are restricted to England; marsh tits prefer open broad leaf forests whereas willow tits prefer damp peat bogs and willow thickets (Perrins et al., 1979), with the two species not typically found in the same areas. We were able to take advantage of the different regional community informant flock compositions created by this natural variation in species distribution to test the effects of different flock compositions on the production and reliability of mobbing calls. 


\section{Reliance on Information by 'Scroungers'}

We focused on dunnocks and European robins as they are commonly found in mixed-species associations with tits throughout the UK and their ecology matches that of satellite species that eavesdrop on community informants (Moynihan, 1962): they are solitary (robin) or found in small groups (dunnocks) during the winter and defend relatively small territories through which other mixed-species flocks travel (Birkhead, 1981; Davies, 1992; Dunn et al., 2004). Both of these species give alarm calls in response to predators (Cramp, 1993b,c; Davies, 1992; Davies et al., 2004) and share predators (e.g., sparrowhawks; merlins, Falco columbarius; kestrels, Falco tinnunculus; and domestic/feral cats, Felis catus) with proposed 'community-informant' species (including tits) in their community (Birkhead, 1981; Cramp, 1993b,c; Cramp \& Perrins 1993; Zawadzka \& Zawadzki, 2001). We focused our analyses on determining how the behavior of robins and dunnocks was affected by the presence of blue, great, and coal tits because these species are found throughout the UK and they vary in the way(s) in which they encode information about predator threat in their mobbing alarm calls (Carlson, Healy et al., 2017).

The number of simulated encounters for both species differed as both dunnocks and robins were not always present at all locations (i.e., a particular bird feeder) during all trials (dunnock: sparrowhawk $n$ $=19$ locations, buzzard $n=25$ locations, partridge $n=17$ locations; robin: sparrowhawk $n=28$ locations, buzzard $n=28$ locations, partridge $n=27$ locations). As willow, crested, or marsh tits were present in all flocks tested (within each species' respective geographical range), we were not able to examine how their presence affected the calling behavior of dunnocks or robins.

\section{Stimuli}

In order to test how reliable the predator threat information produced by Paridae species is and whether it is used by heterospecifics in the community, we conducted predator presentations using three types of robotic taxidermy mounts, which we have previously described in detail (Carlson, Healy et al., 2017; Carlson, Pargeter et al., 2017). We used common buzzards, Buteo buteo, as our low-threat predator because their diet is mainly mammals and larger birds such as pigeons but they do occasionally depredate small birds (ca. 16\% of their diet; Graham et al., 1995; Swann \& Etheridge, 2009). We used sparrowhawks, Accipiter nisus, as our high threat predators because they are small bird specialists with the majority of their diet composed of birds of similar size to tits (ca. 97\% prey by weight; Curio et al., 1983; Millon et al., 2009; Newton, 1986; Petty et al., 1995). We used grey partridge, Pedrix pedrix, as the no-threat controls as they pose no threat to small birds, are common throughout the UK, and are of similar size to sparrowhawks (Cramp, 1993a; Šálek et al., 2004). To reduce pseudoreplication, we used two mounts of each species: two adult male grey partridge, two adult female buzzards, and one adult female and one juvenile male sparrowhawk. The robotics allowed each mount's head to rotate ca. $100^{\circ}$ with the center point facing directly forward in relation to its chest. There were no robotics or related paraphernalia obviously visible on the mounts or the perches that they rested upon.

\section{Predator Presentations}

We carried out these experiments during the winter months, January - March of 2014 and 2015, because mixed-species flocks frequently form during winter (Perrins et al., 1979). We simulated predator encounters by presenting the target species assemblages (mixed-species tit flocks, which included blue, coal, and great tits with either crested, willow, or marsh tits depending on geographic location) with all three of the taxidermy mounts at 54 feeders (locations) in both gardens and forests throughout the UK (23 locations in and around St Andrews, 15 locations in the Highlands, seven locations in Southern England, and nine locations in Monks Wood, Cambridge; see Carlson, Healy et al., 2017 for details and map). Before each trial, we randomly assigned a mount exemplar as well as a predator presentation order to each location. Upon arriving at a location, we placed a $1.5 \mathrm{~m}$ pole, on which the mount would sit, $2 \mathrm{~m}$ 
from the feeder and then visually or acoustically confirmed the presence of a target focal species in the vicinity. We then began recording using a Marantz PMD660 solid-state sound recorder (Marantz America, LLC., Mahwah, N.J., USA) with a bit-depth of 24 bits and a sampling rate of $48 \mathrm{kHz}$, and a Sennheiser ME 66 super-cardioid microphone (Sennheiser Electronics, Hanover, Germany), which we used to record vocalizations of each species, and create verbal annotations of the number of each species present and each individual's behavior, which we could later transcribe. We placed the mount on the pole and then quickly retreated to cover at least 4 (in some small gardens) or 6 (when room was available) meters away. The mount faced the feeder, as predator orientation is an important factor in a predator's perceived level of threat (Book \& Freeberg, 2015). A trial began when an individual bird exhibited any one of several characteristic mobbing behaviors (as defined by Carlson, Healy et al., 2017): 1) approached to a minimum $5 \mathrm{~m}$ of the mount; 2) approached to a minimum $7 \mathrm{~m}$ of the mount keeping its head and body oriented towards the mount for $20 \mathrm{~s}$ more than once in $2 \mathrm{~min}$; or 3) began mobbing the mount (i.e., calling, hopping and flying rapidly between perches, wing-flicking or flip-flopping, or flying aggressively towards the mount; Altmann, 1956). After a focal individual met one of these criteria, we recorded for $5 \mathrm{~min}$ before removing the mount and leaving the area. While distances from the feeder were not marked during each trial, the researchers were trained to reliably determine if the birds were within 3 , 5 , and $7 \mathrm{~m}$ of the mount before the experiment began.

All of our buzzard and sparrowhawk trials were separated by a minimum of $8 \mathrm{hrs}$ at one location if time constraints required presentations to be carried out in one day. When necessary, we also presented a control and a predator presentation on the same day, but in these cases when the non-predator (partridge) was first and no birds changed their feeding behavior in response to this presentation, we waited a shorter period (minimum $15 \mathrm{~min}$ ) before conducting a predator presentation (buzzard: $n=5$, sparrowhawk: $n=6$ trials). During some trials $(n=7)$ birds obviously responded to something other than the stimulus (e.g., behavior suggesting a recent predator encounter (i.e., mobbing something other than the mount, in a different location) or predator flying overhead). As these trials did not represent a response to the presented stimulus, we excluded them from analysis. Due to time constraints, a few locations had only two mount presentations $(n=5)$ while others had only one $(n=3)$.

\section{Acoustic Analysis}

We analysed recordings using Raven Pro v 1.5 acoustical software (Bioacoustics Research Program, 2014) using a Hann window function, a frequency grid resolution of $23.04 \mathrm{~Hz}$, and a fast fourier transformation (FFT) of 1050 samples.

\section{Reliability of 'Community Informants'}

To determine how reliable the assumed 'community-informant' species are across mobbing events, we manually categorized all tit calls by species and type and selected each call (for specifics see Bioacoustics Research Program, 2014; Carlson, Healy et al., 2017; Figure 1a-c). Calls were classified into each call type primarily by $\mathrm{NC}$, but to determine the repeatability of these classifications, we used randomly selected calls of each class and had outside individuals classify them into different call types. The repeatability of $98 \%$ of the calls was high (interclass correlation (ICC) values $>.80$ ). The four call types that had scores lower than this were reclassified by individuals more familiar with the acoustic properties of tit vocalizations, resulting in ICC scores that were all between .77 and 1.0 (with only 1 call type (short calls) receiving a score below .80; Carlson, Healy et al., 2017). 

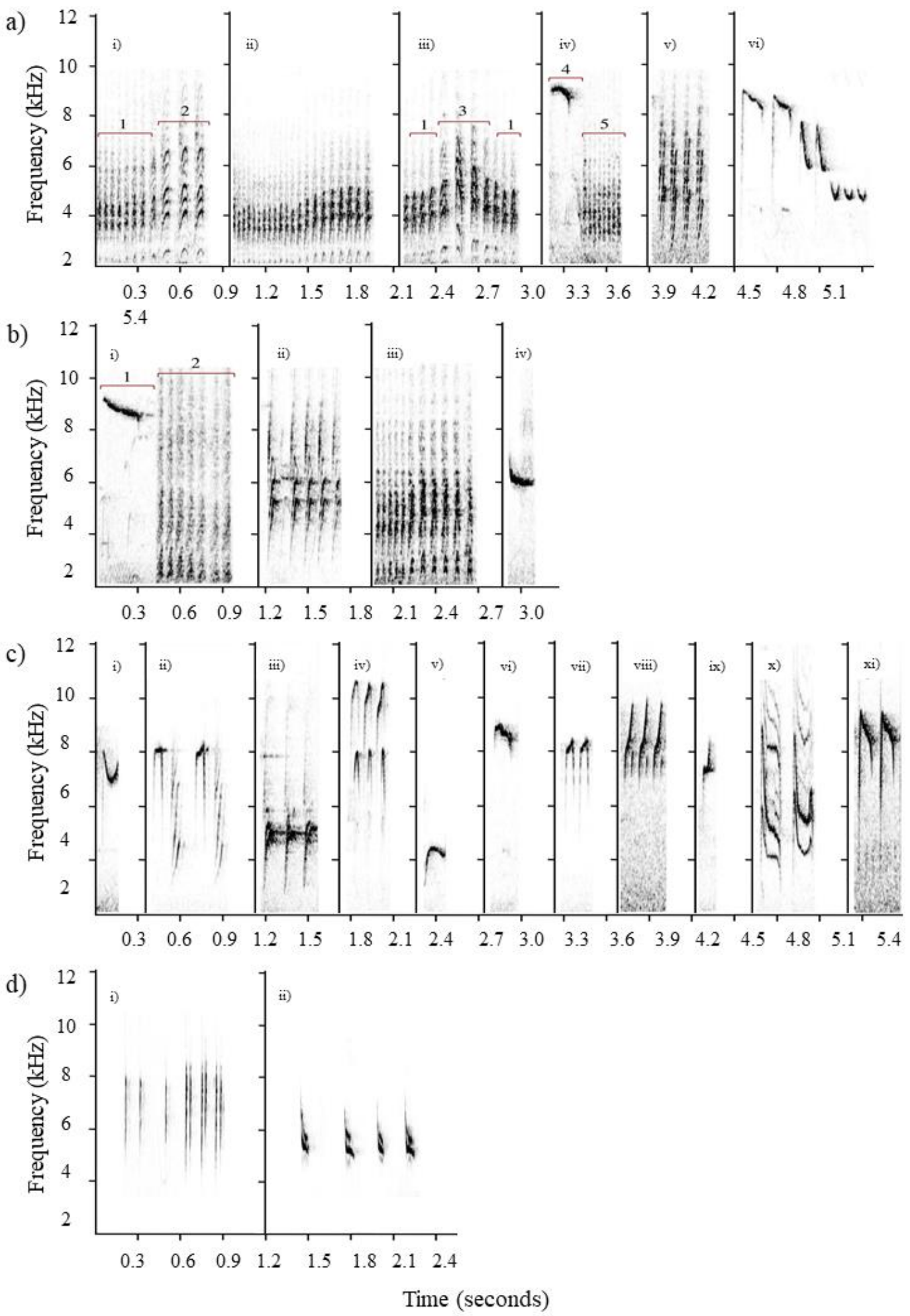

Figure 1. Compiled spectrograms of a) blue tit D (1, i, ii, iii, iv) calls with exit (2), mid (3), intro (4), short (5), and frequencymodulated (ii) elements, and chirp (v), and tonal (vi) calls; b) great tit rattle (i2) calls with intro (i1) element, chirp calls (ii), D calls (iii), and tonal call (iv); coal tit bowl (i), chirp (ii), dot (iii), hook (iv), mound (v), mt (vi), peak (vii), s-dot (viii), s (ix), squeak (x), and slide (xi) calls; d) European robin tick calls (i) and, dunnock calls (ii). 


\section{Use of Information by 'Scroungers'}

To determine if 'information scrounging' species paid attention to 'community informant' calls, we recorded the start and stop time of both tit and robin and dunnock calls, which we did by visually identifying calls belonging to each species (Figure 1d).

\section{Reliance on Information by 'Scroungers'}

To determine whether robins or dunnocks encoded information about predator threat into their calls, we measured three call features for dunnocks and two for robins: 1) call rate: the number of calls/individuals present; 2) peak frequency $(\mathrm{kHz})$ : the frequency at which the most energy occurs; and 3) the call length (seconds) during the three minutes after the onset of mobbing. As robin 'tick' calls are very short in duration, collecting accurate measurements on call length was not possible so we recorded only the first two call features (Figure 1di). Call rate is one of the most commonly measured metrics when examining information coding or perceived threat in anti-predator vocalizations in a variety of species (Carlson, Healy et al., 2017). In addition, we noticed that both peak frequency (robins and dunnocks) and call length (dunnocks) varied across trials, making these variables potential methods in which these species could encode information about predators in their mobbing vocalizations.

\section{Community Composition}

To determine the flock composition during each trial, we recorded the species present and the number of individuals of each tit species present. We focused specifically on tit species as these were a) the community-informant species we were measuring, and b) they formed the bulk of the flock and were the stable flocking individuals. In addition to tits, other species were sometimes present during trials but these species tended to associate less closely with the rest of the flock, appearing to arrive and depart independently during the mobbing events, so we treated these species as non-flock mates (i.e., individuals that may eavesdrop but do not actively travel with the tit flock). Our focal 'scrounger species' also fall into this category, so we did not include the number of robins or dunnocks into our flock composition when testing for reliability of ways in which tits encode information. We used these to determine: 1) the conspecific flock size for each tit species, 2) the total tit flock size, and 3) the presence/absence of each tit species (i.e., heterospecifics). Flock composition and size varied across each mobbing event (mean \pm standard error: $7.47 \pm 0.40$ individuals/flock; number of species: $2.86 \pm 0.09$ species/flock), as well as the average number of conspecifics for each species: (mean \pm standard error): blue: $3.00 \pm 0.21$, great: $2.37 \pm$ 0.14 , coal: $3.51 \pm 0.38$, crested: $1.73 \pm 0.11$, marsh: $1.59 \pm 0.10$, and willow: $1.52 \pm 0.11$. Sample sizes of locations (i.e., feeder where the series of predator presentation trials took place) and trials (one exposure at one feeder to a predator) varied across the different focal species: blue: $n=47$ locations (control $n=41$, buzzard $n=42$, sparrowhawk $n=43$ ), great: $n=43$ locations (control $n=35$, buzzard $n=41$, sparrowhawk $n=42$ ), coal: $n=41$ locations (control $n=34$, buzzard $n=35$, sparrowhawk $n=36$ ), crested: $n=14$ locations (control $n=14$, buzzard $n=14$, sparrowhawk $n=13$ ), marsh: $n=9$ locations (control $n=9$, buzzard $n=9$, sparrowhawk $n=9$ ), and willow: $n=7$ locations (control $n=7$, buzzard $n=$ 6, sparrowhawk $n=7$; Carlson, Healy et al. 2017).

\section{Statistical Analysis}

\section{Reliability of 'Community Informants'}

To test the effect of community composition on how reliably different tit species ('community informants') encoded information about predator threat (i.e., whether they varied acoustic metrics only in response to predator threat or whether variation in their acoustic metrics was sensitive to the number of conspecifics, the presence of heterospecifics, or the flock size), we ran linear mixed and generalized linear 
mixed models on element/call types for all four encoding methods used by tit species: call rate (calls/individual/minute), number of elements/notes in a call: element number, proportion of calls during a mobbing event of one type: proportion, and propensity for a call type to be used across mobbing events: propensity. To test how the number of conspecifics affected ways of encoding information in calls, we included a fixed effect of conspecific number; to test how the presence of other species affected encoding methods we included terms for the presence/absence of blue tits, great tits, and coal tits; however, due to experimental design, we could test only the blue, great, coal, and crested tit data as blue and great tits were always present and coal tits were almost never present when marsh or willow tits were present. To test how the size of the flock affected encoding methods, we included flock size as a fixed effect. As, however, flock size and number of conspecifics were positively correlated for blue, great, and coal tits, we included only the number of conspecifics in the models for these three species. We included mount presentation order, and mount exemplar as fixed effects as they were part of the experimental design and had fewer than five levels, which made them inappropriate as random effects (Harrison et al., 2018). We did see order and exemplar effects in the models, but none of these effects were consistent across responding species, element/call type, stimulus species, or encoding methods. We also included random effects of geographic area, and a term (trial) that accounted for multiple calls produced at each location to reduce pseudoreplication. For any linear models that had non-normal residuals, we used a log or boxcox transformation to normalize the residuals. In several instances, models could not converge if stimulus:order or stimulus:mount exemplar levels were all 1 or 0 so we fitted these using linear models instead. For each model, we tested for an effect of the number of conspecifics, the presence of blue, great, and/or coal tits, and the flock size using III Wald Chi squared tests.

\section{Use of Information by 'Scroungers'}

To test whether robins or dunnocks ('information scroungers') 'pay attention' to community informants, we determined whether dunnocks or robins overlapped their calls with calls produced by nuclear species using a program called song overlap null model generator (SONG; Masco et al., 2015). This program takes the total call length and inter-call interval of both species and randomizes them in order to generate a distribution of the number of calls that should overlap for each species by chance. This method takes into account the species-specific differences in call rate, length, and inter-call interval when determining and producing the overlap matrix for all species. This allowed us to test whether the number of calls that robins and dunnocks produced that overlapped blue, great, or coal tit, and each other's calls were likely to be due to avoidance, to overlap, or to chance. For each species pair, we included calling data only where we had visual confirmation of the presence of both species being compared. For this analysis, we treated each species as an 'individual' as it is designed to compare the singing behavior of individuals.

\section{Reliance on Information by 'Scroungers'}

To test whether robins or dunnocks encoded information about predator threat in their own calls, we generated linear mixed models with a Gaussian error structure. We constructed separate models for robins and dunnocks as each had a different call (Figure 1). We generated a separate model for call rate, peak frequency, and call length to test each encoding method separately, as they may not be correlated with one another. We included the call feature (call rate, peak frequency, or length) as the response variable and predator threat level as a fixed effect. Due to tit species usually arriving to high threat mobbing events shortly after they began (if they were not themselves the instigators), there were very few mobbing events (sparrowhawk | buzzard) where robins and/or dunnocks were present but tit species were absent (dunnocks- blue tits: 0 | 3 locations, great tits: 2 | 7 locations, coal tits: $7 \mid 11$ locations; robins blue tits: 1 | 4 locations, great tits: 4 | 6 locations, coal tits: 8 | 12). This low sample size, and accompanying low statistical power, prohibits analyses of the responses to specific tit species. Therefore, we instead tested if dunnocks and robins encode information in their calls about predator threat regardless 
of which tit species were present. To account for experimental design, we included the mount exemplar and order, the number of conspecifics, and the flock size as fixed effects and included location, and a term (trial) to account for multiple calls at each location as random effects. Due to non-normal residuals, all response variables were log-transformed, except for robin peak frequency, which was squared. We ran type II Wald Chi-square tests on each model to test for significant effects of stimulus, or the presence of community-informant species on call feature, as we were not interested in interactions. We used R v3.6.1 (R Core Team, 2014) and the lme4 package (Bates et al., 2016) to conduct all of the statistical analyses.

Here, we discuss only the significant results; for complete model results please see Tables A1-A6 in the appendix (tits), and Table 1 (dunnocks \& robins).

\section{Ethical Note}

This research was approved by the School of Biology Ethics Committee (0112013) at the University of St Andrews as well as by Scottish National Heritage and adhered to ASAB/ABS guidelines for the treatment of animals in research. Due to the potential stress of low temperatures during the winter months when we conducted these experiments, we restricted all predator presentations to times between one hour after sunrise and one hour before sunset. This allowed individuals to recover from the hours of darkness and prepare for overnight un-stressed by artificial predators. Additionally, we minimized the time a predator was presented for to 5 min after individuals initiated responding and removed the stimulus and vacated the area as quickly as possible once the 5 min were up to allow the animals to recover and resume natural foraging behavior.

\section{Results}

\section{Reliability of 'Community Informants'}

Blue, great, and coal tits were the most reliable as they each had at least one way of encoding information about predator threat that was not influenced by flock structure. Blue tits varied their propensity to produce mid elements, frequency modulated, and short calls (mid: $\chi^{2}=27.70, p<.001$, frequency-modulated: $\chi^{2}=13.88, p=.001$, short: $\chi^{2}=22.20, p<.001$; Table A1), great tits varied their call rate $\left(\chi^{2}=6.23, p=.044\right.$; Table A2), and coal tits varied their call rate, the number of mt elements, and the propensity to use mound and squeak elements (rate: $\chi^{2}=20.64, p<.001$, mt: $\chi^{2}=13.48, p=.001$, mound: $\chi^{2}=6.19, p=.045$, squeak: $\chi^{2}=8.40, p=.015$; Table A3) in response to predator threat, but not to the number of conspecifics or the presence of heterospecifics.

In contrast, some of the other ways blue, great, and coal tits encode information about predator threat in their calls were, in fact, affected by community composition, and therefore, not reliable sources of information about predator threat. All other ways of encoding information used by blue, great, and coal tits were affected by either the number of conspecifics or the presence of heterospecifics. Blue tits varied their call rate, number of $\mathrm{D}$ elements, the proportion of exit and chirp elements, and their propensity to produce exit elements in response to predator threat depending on the number of conspecifics present and/or the presence of great and/or coal tits (rate: $\chi^{2}=8.80, p=.012$ (conspecifics), D: $\chi^{2}=22.11, p<$ .001 (conspecifics), $\chi^{2}=7.49, p=.024$ (great tits), $\chi^{2}=20.37, p<.001$ (coal tits), exit (proportion): $\chi^{2}=$ $12.50, p=.002$ (conspecifics), $\chi^{2}=15.57, p<.001$ (coal tit), chirp: $\chi^{2}=12.71, p=.002$ (conspecific), $\chi^{2}$ $=11.60, p=.003$ (great tit), exit (propensity): $\chi^{2}=6.54, p=.038$ (great tit); Table A1). Blue tits also increased the number of total calls, tonal calls, and their propensity to use exit elements and tonal calls as the number of conspecifics increased (calls: $\chi^{2}=5.23, p=.022$, tonal (proportion): $\chi^{2}=8.34, p=.004$, exit: $\chi^{2}=4.84, p=.028$, tonal (propensity): $\chi^{2}=5.24, p=.022$ ), produced more total elements but a lower call rate when great tits were present (elements: $\chi^{2}=7.04, p=.008$, rate: $\chi^{2}=5.27, p=.022$ ), and decreased the number of total elements when coal tits were present $\left(\chi^{2}=5.28, p=.022\right.$; Table A1). Great tits varied the number of total calls and the proportion of chirp calls in response to predator threat 
depending on the number of conspecifics and/or presence of coal tits (calls: $\chi^{2}=6.91, p=.032$, chirp: $\chi^{2}$ $=15.75, p<.001$ (conspecific), $\chi^{2}=24.9, p<.001$ (coal tit); Table A2); they did not encode predator threat information in their propensity to use jar/rattle calls (Table A2). Coal tits varied the number of total calls, hook, mound, and s-dot elements in response to predator threat depending on the number of conspecifics and/or the presence of blue or great tits (calls: $\chi^{2}=6.14, p=.046$ (blue tit), hook: $\chi^{2}=$ 12.07, $p=.002$ (conspecifics), $\chi^{2}=8.07, p=.018$ (great tit), mound: $\chi^{2}=5.70, p=.017$ (great tit), s-dot: $\left.\chi^{2}=6.42, p=.040\right)$ and decreased the number of s-dot elements as the number of conspecifics increased $\left(\chi^{2}=4.96, p=.026\right)$; they did not encode predator threat information in the number of squeak elements (Table A3).

Unlike the other three species, crested, marsh, and willow tits did not have any ways of encoding information about predator threat (i.e., the ways they varied call elements in response to different predators) that were not influenced by flock structure, and therefore did not reliably encode predator threat information in their calls (Table A4-6). Crested tits varied the number of calls and the proportion of frequency-modulated calls they produced in response to predators depending on the flock size or the number of conspecifics and the presence of blue and great tits respectively (calls: $\chi=6.03, p=.049$ (flock size), frequency-modulated: $\chi^{2}=27.93, p<.001$ (conspecifics), $\chi^{2}=10.30, p=.006$ (blue tit), $\chi^{2}$ $=8.42, p=.015$ (great tit); Table A4). They also increased their call rate as flock size increased $\left(\chi^{2}=\right.$ $4.50, p=.034$ ) and decreased their call rate and number of calls when blue tits were present (rate: $\chi^{2}=$ 9.8, $p=.002$, calls: $\chi^{2}=11.40, p=.001$ ); they did not encode predator threat in the proportion of total calls they produced (Table A4). Marsh tits varied the proportion of full total elements in response to predator threat depending on both the number of conspecifics and flock size $\left(\chi^{2}=5.11, p=.024\right.$ (conspecifics), $\chi^{2}=6.29, p=.043$ (flock size)), and increased the number of Dä/D elements as the number of conspecifics increased $\left(\chi^{2}=6.65, p=.010\right)$; they did not encode predator threat in their propensity to use tonal, peak tonal elements, or ptew calls (Table A5). Willow tits varied their call rate, number of calls, the total number of elements, and their propensity to use zizi calls in response to predator threat depending on the number of conspecifics and/or the flock size (rate: $\chi^{2}=9.82, p=.007$ (flock size), calls: $\chi^{2}=10.95, p=.004$ (flock size), elements: $\chi^{2}=7.17, p=.028$ (conspecifics), zizi: $\chi^{2}=9.12$, $p=.010$ (conspecifics), $\chi^{2}=94.71, p<.001$ (flock size)); they did not encode predator threat information in the number of si intro elements they produced (Table A6).

\section{Use of Information by 'Scroungers'}

Robins avoided overlapping their calls with blue, great, and coal tits more often than by chance given their respective call lengths, rates, and inter-call intervals, and neither avoided nor overlapped calling with dunnocks (blue tit: $p<.010$; great tit: $p<.010$; coal tit: $p<.010$; dunnock: $p=.170$ ). Dunnocks did not avoid or overlap their calls with those of blue tits, coal tits, or robins, but they did avoid calling when great tits were calling (blue tit: $p=.450$; great tit: $p<.010$; coal tit: $p=.090$; robin: $p=$ $.650)$.

\section{Reliance on Information by 'Scroungers'}

Robins increased their call rate, but not their peak frequency, in response to predators compared to controls (call rate: $\chi^{2}=6.07, p=.048$; peak frequency: $\chi^{2}=1.45, p=.486$; Table 1; Figure 1). There was an interaction of stimulus and order in both models but with no consistent pattern (call rate: $\chi^{2}=$ 9.79, $p=.044$; peak frequency: $\chi^{2}=25.22, p<.001$ )

Dunnocks also increased their call rate, but not their peak frequency or call length, in response to predators compared to the control (call rate: $\chi^{2}=17.53, p<.001$; peak frequency: $\chi^{2}=4.83, p=.089$, call length: $\chi^{2}=2.08, p=.353$; Table 1; Figure 2). For peak frequency, as the number of conspecifics increased the peak frequency decreased $\left(\chi^{2}=55.37, p<.001\right.$, Table 1$)$, and there was an order effect, in that the final stimulus had a shorter call length than the first presentation $\left(\chi^{2}=8.95, p=.011\right.$, Table 1$)$. 
Carlson et al. 225

Table 1

Model Summary for Linear Mixed Models Testing for Predator Type on ways of Encoding Information about Predator Threat for a) Dunnocks, and b) Robins

\begin{tabular}{|c|c|c|c|c|c|c|c|c|c|c|}
\hline Call rate & $\chi^{2}$ & $\mathrm{df}$ & $p$ & Peak frequency & $\chi^{2}$ & $\mathrm{df}$ & Call length & $\chi^{2}$ & df & $p$ \\
\hline \multicolumn{11}{|c|}{ a) dunnocks } \\
\hline Stimulus & 17.53 & 2 & $<.00$ & 1 Stimulus & 4.83 & 2 & .089 Stimulus & 2.08 & 2 & .353 \\
\hline Order & 0.01 & 2 & & 3 Order & 4.37 & 2 & .112 Order & 8.95 & 2 & .011 \\
\hline Mount & 0.03 & 1 & .85 & 5 Mount & 0.42 & 1 & .518 Mount & 0.06 & 1 & .809 \\
\hline Num. dunnocks & 0.30 & 1 & .58 & 5 Num. dunnocks & 55.37 & 1 & $<.001$ Num. dunnocks & 0.25 & 1 & .619 \\
\hline Flock size & 0.36 & 1 & .54 & 9 Flock size & 3.14 & 1 & .076 Flock size & 0.00 & 1 & .967 \\
\hline Stimulus:Order & 2.63 & 4 & .62 & 1 Stimulus:Order & 2.56 & 4 & .635 Stimulus:Order & 5.65 & 4 & .227 \\
\hline Stimulus:Mount & 0.92 & 2 & .63 & 2 Stimulus:Mount & 0.59 & 2 & .746 Stimulus:Mount & 0.09 & 2 & .954 \\
\hline \multicolumn{11}{|c|}{ b) robins } \\
\hline Stimulus & 6.07 & 2 & .04 & 8 Stimulus & 1.45 & 2 & .485 & & & \\
\hline Order & 1.25 & 2 & .53 & 6 Order & 6.01 & 2 & .050 & & & \\
\hline Mount & 2.47 & 1 & .11 & 6 Mount & 0.43 & 1 & .510 & & & \\
\hline Num. robins & 0.05 & 1 & .82 & 9 Num. robins & 0.29 & 1 & .591 & & & \\
\hline Flock size & 0.11 & 1 & .74 & 0 Flock size & 1.13 & 1 & .288 & & & \\
\hline Stimulus:Order & 9.79 & 4 & .04 & 4 Stimulus:Order & 25.22 & 4 & $<.001$ & & & \\
\hline Stimulus:Mount & 0.25 & 2 & .88 & 4 Stimulus:Mount & 1.04 & 2 & .596 & & & \\
\hline
\end{tabular}

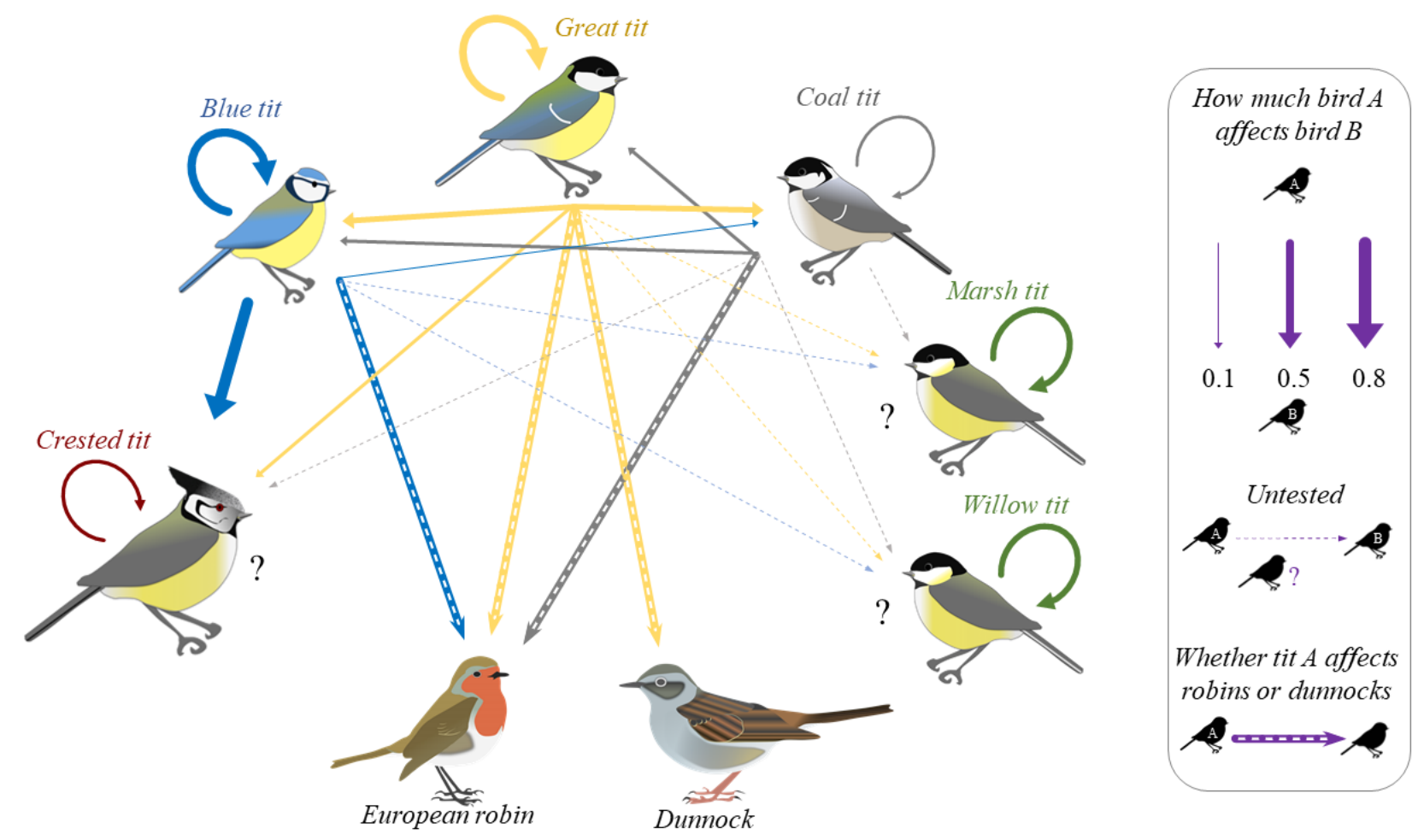

Figure 2. A representation of the influence different species have on conspecific and heterospecific calling behavior. Arrows represent the relative strength of effect on recipient's calling behavior (encoding strategies influenced by a species/total encoding strategies - tits) or whether they 'avoid' calling when another species calls - dunnocks and robins), arrow direction indicates influence of one species on another, small dashed lines/question marks indicate untested effects of other birds on focal bird (dashed lines) or effects of focal bird on other birds (question mark), and no lines show a lack of an effect (robins and dunnocks were tested only for effects on each other's calling behavior, and whether they were affected by blue, great, and coal tits). Arrow color indicates which bird is affecting another. 


\section{Discussion}

Only a few of the presumed 'community informant' species (blue, coal and great tits) were actually reliable in the way they encoded information about predator threat, meaning that half did not meet the criteria to be considered a community informant. Additionally, the species that consistently produced information about predator threat were not equally relied on by 'scrounger' species. Of the two 'scrounger' species, robins appeared to 'pay attention' to the information from multiple species, while dunnocks used only one. Additionally, both species were able to encode predator presence in their own mobbing calls. This shows that not all species that appear to be good community informants due to the information they produce about predator threat actually serve that purpose in their communities. Additionally, these results highlight the lack of understanding of information scrounger species, the role they do or do not play in their communities, and their reliance on community informants.

Only one species of tit met the criteria of a community informant by (1) producing reliable information about predator threat independent of group size and composition, (2) have that information used by 'scrounger' species, and (3) be used by more than one 'scrounger' species (i.e., the community). Great tits produced at least one way of encoding information about predator threat in their mobbing calls that was independent of flock size or composition. This information was used by both robins and dunnocks (i.e., they avoided calling when blue and great tits called - thereby 'paid attention' to the calls), and robins and dunnocks relied on this information (i.e., their own calls do not differentiate between different threat predators, though they do encode predator presence). This suggests that great tits may be community informants. However, while great tits may be community informants, they may not be the exclusive source of information for all community members, as both dunnocks and robins produced their own information in the presence of a predator. Additionally, great tits also show that the number of ways in which a species encodes information about predator threat in their calls is not necessarily correlated with whether a species is a community informant as, while blue and coal tits use many different ways of reliably encoding threat information in their call structure, great tits use only one (Carlson, Healy et al., 2017).

Blue and coal tits met some but not all of the criteria for community informants. They (1) produce reliable information about predator threat independent of group size and composition, and (2) that information is used by 'scrounger' species. However, only one species used this information, and that species did not rely solely on one 'community informant' species. Both blue and coal tits encoded information about predator threat in multiple ways that were unaffected by flock size or composition. Robins used this information (i.e., avoided overlapping their calls) but did not rely exclusively on it (used other information sources) and this information was used by only one of the two 'scroungers' tested. Due to the multiple ways blue and coal tits reliably encode information in their calls, the lack of reliance of robins (and response by dunnocks) to this information was surprising. However, it is possible that blue and coal tits are nonetheless useful informants; just because the studied 'scrounger' species do not rely solely on the information encoded in their calls, this does not mean other species do not. Robins and dunnocks are unlikely to be the only information scroungers in the wider community and blue and coal tit mobbing calls may be used as sources of information by other species, just not by the community as a whole (Carlson, Healy et al., 2017).

Unexpectedly, the remaining three Paridae species (crested, marsh, and willow tits) do not meet any of the criteria necessary for being community informants. Like many other species (buff-streaked chats, Oenanthe bifasciata, (Seoraj-Pillai \& Malan, 2014), Thomas langurs, Presbytis thomasi, (Wich \& Sterck, 2003), and drongos, Dicrurus adsimilis, (Ridley et al., 2007), the information that crested marsh, and willow tits produce about predators varies with flock structure and would not be readily interpretable by itinerants. Crested, marsh, and willow tits do not, therefore, meet the community informant criteria, although they may still provide information for familiar conspecific and heterospecific receivers within their flocks.

Our results bring into question some of the social and ecological factors that are assumed to result in a species being a 'community informant.' While certain ecological factors may indicate that a 
particular species is a community informant, it appears that not all species with those ecological factors actually serve as such for their community. Similar to orange-billed babblers, Turdoides rufescens, in Sri Lankan mixed-species flocks, while some tit species appear to fit the ecology of a 'community informant' and frequently produce alarm calls, their unreliability should preclude them from being important sources of information about predators for information scroungers (Goodale \& Kotagama, 2005a, b, 2008). However, individual species can still be important sources of information, even when their vocal behavior is influenced by flock size and composition. If, as in many tropical mixed-species flocks, the flock composition and structure remain the same across time, then this stability will mitigate the impact of flock structure on the signals produced by 'community informant' species. This could allow species with sensitive encoding strategies to be important sources of information, only at a flock rather than community level. With relatively stable flock assemblages, it could be argued that this type of threatsensitive information could even be more useful to some receivers.

To determine that a species is a community informant, one must demonstrate not only that it produces calls uninfluenced by flock structure, but also that multiple heterospecifics use this information. Given these criteria, while both robins and dunnocks seem to fit the description of an information scrounger to a certain extent, they do so to different degrees. While both species were able to encode predator presence in their mobbing calls, they varied in how much heterospecific information they 'paid attention' to (did not overlap their calling with). While robins appeared to attend to blue, great, and coal tits, dunnocks attended only to great tits, suggesting that the information tits produce in general is more pertinent for robins than dunnocks. This difference in response by dunnocks and robins might have been expected because, although dunnocks and robins are both commonly found associating with tit flocks, there are potential differences between dunnocks and robins in their vulnerability to shared predators: robins and dunnocks vary from one another in their relative predation risk to sparrowhawks and compared to blue and great tits across seasons and years (Davies, 1992). This difference in vulnerability to sparrowhawks compared to tits may make tits a less relevant signaller for dunnocks compared to robins. Although both dunnocks and robins forage primarily on and near the ground (Cramp, 1993b,c; Davies, 1992; Lack, 1948), robins sing year-round from perches at similar heights to where blue tits tend to forage (Cramp, 1993c; Cramp \& Perrins 1993; Davies, 1992; Lack, 1948). As positions on the ground or lower vegetation can increase predation risk, increased time spent perched at higher positions while highly vigilant (Davies, 1992) may make robin predation risk more closely match that of high foraging blue tits. Additionally, while tits, robins, and dunnocks are frequently hunted by sparrowhawks, tits and robins are more well represented in the sparrowhawk's diet than dunnocks even given their relative abundance (Newton, 1986). This difference in vulnerability may make the information from blue tits less pertinent or reliable to dunnocks (Magrath et al., 2014), resulting in differences in information use across species (Forsman \& Mönkkönen, 2001; Magrath et al., 2009; Rainey et al., 2004a, b). Just as it is not as straightforward to determine which species are community informants, deciding which species are information scroungers, and to what degree, may require more information than just their peripheral or temporary position in a flock.

In conclusion, our data show that a species' ecology may not be the best predictor of their role as an 'information source' or as an 'information scrounger.' Before assigning a species as a community informant (i.e., a key information source), it would be useful to determine whether its calls differentiate between predator threat, are independent of flock structure, are used by multiple scrounger species, and whether those scrounger species rely exclusively on this information. Given many of our putative 'community informants' and 'information scroungers' (classified according to frequently used ecological characteristics) did not in fact meet the criteria to be classified as such, we may need to further examine previously classified species to affirm the role they play in their species' communities. Additionally, as there appears to be variation in the amount and quality of information produced and used across both informant and scrounger species, we suggest that, similar to discussions of nuclearity in mixed-species flock literature (Farley et al., 2008; Gentry et al., 2019; Harrison \& Whitehouse, 2011; Mammides et al., 2018; Srinivasan et al., 2010), we should shift our focus from a dichotomy of community informants and 
scroungers to a continuum of information production based not only the production of reliable information but also on the use of that information by other species in the community.

\section{References}

Altmann, S. A. (1956). Avian mobbing behavior and predator recognition. Condor, 58, 241-253.

Baker, M. C., \& Becker, A. M. (2002). Mobbing calls of black-capped chickadees: Effects of urgency on call production. The Wilson Bulletin, 114, 510-516.

Bartmess-LeVasseur, J., Branch, C. L., Browning, S. A., Owens, J. L., \& Freeberg, T. M. (2010). Predator stimuli and calling behavior of Carolina chickadees (Poecile carolinensis), tufted titmice (Baeolophus bicolor), and white-breasted nuthatches (Sitta carolinensis). Behavioral Ecology and Sociobiology, 64, 1187-1198.

Bates, D. M., Maechler, M., Bolker, B. M., \& Walker, S. (2016). Fitting linear mixed-effects models using lme4. Journal of Statistical Software, 67, 1-48.

Bee, M. A., \& Micheyl, C. (2008). The cocktail party problem: What is it? How can it be solved? And why should animal behaviorists study it? Journal of Comparative Psychology, 122, 235-251.

Bioacoustics Research Program. (2014). Raven Pro: Interactive sound analysis software (Version 1.5). Ithaca, NY: The Cornell Lab of Ornithology. Retrieved from http://www.birds.cornell.edu/raven

Birkhead, M. E. (1981). The social behavior of the dunnock Prunella modularis. Ibis, 123, 75-84.

Blumstein, D. T., \& Armitage, K. B. (1997). Does sociality drive the evolution of communicative complexity? A comparative test with ground-dwelling sciurid alarm calls. American Naturalist, 150, 179-200.

Blumstein, D. T., Evans, C. S., \& Daniel, J. C. (1999). An experimental study of behavioural group size effects in tammar wallabies, Macropus eugenii. Animal Behaviour, 58, 351-360.

Book, D. L., \& Freeberg, T. M. (2015). Titmouse calling and foraging are affected by head and body orientation of cat predator models and possible experience with real cats. Animal Cognition, 18, 1155-1164.

Carlson, N. V., Greene, E., \& Templeton, C. N. (2020). Nuthatches vary their alarm calls based upon the source of the eavesdropped signals. Nature Communications, 11, 526.

Carlson, N. V., Healy, S. D., \& Templeton, C. N. (2017). A comparative study of how British tits encode predator threat in their mobbing calls. Animal Behaviour, 125, 77-92.

Carlson, N. V., Pargeter, H. M., \& Templeton, C. N. (2017). Sparrowhawk movement, calling, and presence of dead conspecifics differentially impact blue tit (Cyanistes caeruleus) vocal and behavioral mobbing responses. Behavioral Ecology and Sociobiology, 71, 133.

Caro, T. M. (2005). Antipredator defenses in birds and mammals. The University of Chicago Press.

Cheney, D. L., \& Seyfarth, R. M. (1985). Vervet monkey alarm calls: manipulation through shared information? Behaviour, 94, 150-166.

Clucas, B. A., Freeberg, T. M., \& Lucas, J. R. (2004). Chick-a-dee call syntax, social context, and season affect vocal responses of Carolina chickadees (Poecile carolinensis). Behavioral Ecology and Sociobiology, 57, 187-196.

Courter, J. R., \& Ritchison, G. (2010). Alarm calls of tufted titmice convey information about predator size and threat. Behavioral Ecology, 21, 936-942.

Cramp, S. (1993a). Partridge. In K. E. L. Simmons, R. Gillmor, P. A. D. Hollom, R. Hudson, E. M. Nicholson, M. A. Ogilvie, P. J. S. Onley, C. S. Roselaar, K. H. Voous, D. I. M. Wallace, J. Wattel (Eds.). Handbook of the birds of Europe the Middle East and North Africa. Volume II. Hawks to Buztards (pp. 486-495). Oxford University Press.

Cramp, S. (1993b). Dunnock. In D. J. Brooks, E. Dunn, R. Gillmor, J. Hall-Craggs, P. A. D. Hollom, E. M. Nicholson, M. a. Ogilvie, C. S. Roselaar, P. J. Sellar, K. E. L. Simmons, K. H. Voos, D. I. M. Wallace, M. G. Wilson (Eds.). Handbook of the birds of Europe the Middle East and North Africa. Volume V. Tyrant Flycatchers to Thrushes (pp. 548-559). Oxford University Press.

Cramp, S. (1993c). Robin. In D. J. Brooks, E. Dunn, R. Gillmor, J. Hall-Craggs, P. A. D. Hollom, E. M. Nicholson, M. a. Ogilvie, C. S. Roselaar, P. J. Sellar, K. E. L. Simmons, K. H. Voos, D. I. M. Wallace, M. G. Wilson (Eds.). Handbook of the birds of Europe the Middle East and North Africa. Volume V. Tyrant Flycatchers to Thrushes (pp. 596-615). Oxford University Press.

Cramp, S., \& Perrins, C. M. (1993). Paridae. In D. J. Brooks, E. Dunn, R. Gillmor, J. Hall-Craggs, B. Hillcoat, P. A. D. Hollom, E. M. Nicholson, C. S. Roselaar, W. T. C. Seale, P. J. Sellar, K. E. L. Simmons, D. W. Snow, D. Vincent, K. H. Voous, D. I. M. Sallace, M. G. Wilson (Eds.). Handbook of the birds of Europe the Middle East and North Africa. Volume VII. Flycatchers to Shrikes (pp. 145-281). Oxford University Press. 
Curio, E. (1978). The adaptive significance of avian mobbing. I. Teleonomic hypotheses and predictions. Zeitschrift Für Tierpsychologie - Journal of Comparative Ethology, 48, 175-183.

Curio, E., Klump, G. M., \& Regelmann, K. (1983). An anti-predator response in the great tit (Parus major): Is it tuned to predator risk? Oecologia, 60, 83-88.

Davies, N. B. (1992). Dunnock behaviour and social evolution. Oxford University Press.

Davies, N. B., Madden, J. R., \& Butchart, S. H. M. (2004). Learning fine-tunes a specific response of nestlings to the parental alarm calls of their own species. Proceedings of the Royal Society B: Biological Sciences, 271, 2297-2304.

Dunn, M., Copelston, M., \& Workman, L. (2004). Trade-offs and seasonal variation in territorial defence and predator evasion in the European robin. Ibis, 146, 77-84.

Evans, C. S., Macedonia, J. M., \& Marler, P. (1993). Effects of apparent size and speed on the response of chickens, Gallus gallus, to computer-generated simulations of aerial predators. Animal Behaviour, 46, 1-11.

Fallow, P. M., \& Magrath, R. D. (2010). Eavesdropping on other species: Mutual interspecific understanding of urgency information in avian alarm calls. Animal Behaviour, 79, 411-417.

Farley, E. A., Sieving, K. E., \& Contreras, T. A. (2008). Characterizing complex mixed-species bird flocks using an objective method for determining species participation. Journal of Ornithology, 149, 451-468.

Fichtel, C., \& Manser, M. (2010). Vocal communication in social groups. In P. Kappeler (Ed.), Animal Behavior: Evolution and Mechanisms (pp. 29-54). Springer Berlin Heidelberg.

Ficken, M. S., \& Popp, J. W. (1996). A comparative analysis of passerine mobbing calls. The Auk, 113, 370-380.

Forsman, J. T., \& Mönkkönen, M. (2001). Responses by breeding birds to heterospecific song and mobbing call playbacks under varying predation risk. Animal Behaviour, 62, 1067-1073.

Fuong, H., Keeley, K. N., Bulut, Y., \& Blumstein, D. T. (2014). Heterospecific alarm call eavesdropping in nonvocal, white-bellied copper-striped skinks, Emoia cyanura. Animal Behaviour, 95, 129-135.

Gentry, K. E., Roche, D. P., Mugel, S. G., Lancaster, N. D., Sieving, K. E., Freeberg, T. M., \& Lucas, J. R. (2019). Flocking propensity by satellites, but not core members of mixed-species flocks, increases when individuals experience energetic deficits in a poor-quality foraging habitat. PLoS ONE, 14, e0209680-29.

Gill, S. A., \& Bierema, A. M. K. (2013). On the meaning of alarm calls: A review of functional reference in avian alarm calling. Ethology, 119, 449-461.

Goodale, E., \& Beauchamp, G. (2010). The relationship between leadership and gregariousness in mixed-species bird flocks. Journal of Avian Biology, 41, 99-103.

Goodale, E., Beauchamp, G., Magrath, R. D., Nieh, J. C., \& Ruxton, G. D. (2010). Interspecific information transfer influences animal community structure. Trends in Ecology \& Evolution, 25, 354-361.

Goodale, E., \& Kotagama, S. W. (2005a). Alarm calling in Sri Lankan mixed-species bird flocks. The Auk, 122, $108-120$.

Goodale, E., \& Kotagama, S. W. (2005b). Testing the roles of species in mixed-species bird flocks of a Sri Lankan rain forest. Journal of Tropical Ecology, 21, 669-676.

Goodale, E., \& Kotagama, S. W. (2008). Response to conspecific and heterospecific alarm calls in mixed-species bird flocks of a Sri Lankan rainforest. Behavioral Ecology, 19, 887-894.

Goodale, E., \& Ruxton, G. D. (2010). Antipredator benefits from heterospecifics. In M. D. Breed \& M. J (Eds.), Encyclopedia of Animal Behavior (Vol. 1, pp. 94-99). Academic Press.

Grade, A. M., \& Sieving, K. E. (2016). When the birds go unheard: Highway noise disrupts information transfer between bird species. Biology Letters, 12, 1-4.

Graham, I. M., Redpath, S. M., \& Thirgood, S. J. (1995). The diet and breeding density of common buzzards Buteo buteo in relation to indices of prey abundance. Bird Study, 42, 165-173.

Griesser, M. (2008). Referential calls signal predator behaviour in a group-living bird species. Current Biology, 18, 69-73.

Griesser, M. (2009). Mobbing calls signal predator category in a kin group-living bird species. Proceedings of the Royal Society B: Biological Sciences, 276, 2887-2892.

Griesser, M., \& Ekman, J. (2004). Nepotistic alarm calling in the Siberian jay, Perisoreus infaustus. Animal Behaviour, 67, 933-939.

Griesser, M., \& Ekman, J. (2005). Nepotistic mobbing behaviour in the Siberian jay, Perisoreus infaustus. Animal Behaviour, 69, 345-352.

Hamilton, W. D. (1971). Geometry for the selfish herd. Journal of Theoretical Biology, 31, 295-311.

Harrison, X. A., Donaldson, L., Correa-Cano, M., E., Evans, J., Fisher, D., N., Goodwin, C., E., Robinson, B., S., Hodgson, D., J., \& Inger, R. (2018). A brief introduction to mixed effects modelling and multi-model inference in ecology. Peer J, 6, e4794. 
Harrison, N. M., \& Whitehouse, M. J. (2011). Mixed-species flocks: An example of niche construction? Animal Behaviour, 81, 675-682.

Hetrick, S. A., \& Sieving, K. E. (2011). Antipredator calls of tufted titmice and interspecific transfer of encoded threat information. Behavioral Ecology, 23, 83-92.

Igic, B., Ratnayake, C. P., Radford, A. N., \& Magrath, R. D. (2019). Eavesdropping magpies respond to the number of heterospecifics giving alarm calls but not the number of species calling. Animal Behaviour, 148, 133143.

Karakashian, S. J., Gyger, M., \& Marler, P. (1988). Audience effects on alarm calling in chickens (Gallus gallus). Journal of Comparative Psychology, 102, 129-135.

Krama, T. (2007). Mobbing behavior in birds: Costs and reciprocity based cooperation [Unpublished doctoral dissertation]. Tartu University.

Krams, I. A. (2001). Communication in crested tits and the risk of predation. Animal Behaviour, 61, 1065-1068.

Lack, D. (1948). Notes on the ecology of the robin. Ibis, 90, 252-279.

Landsborough, B., Wilson, D. R., \& Mennill, D. J. (2019). Variation in chick-a-dee call sequences, not in the fine structure of chick-a-dee calls, influences mobbing behavior in mixed-species flocks. Behavioral Ecology, 6, e23844-9.

Lea, A. J., Barrera, J. P., Tom, L. M., \& Blumstein, D. T. (2008). Heterospecific eavesdropping in a nonsocial species. Behavioral Ecology, 19, 1041-1046.

Lilly, M. V., Lucore, E. C., \& Tarvin, K. A. (2019). Eavesdropping grey squirrels infer safety from bird chatter. PLOS ONE 14, e0221279.

Magrath, R. D., \& Bennett, T. H. (2012). A micro-geography of fear: learning to eavesdrop on alarm calls of neighbouring heterospecifics. Proceedings of the Royal Society B: Biological Sciences, 279, 902-909.

Magrath, R. D., Haff, T. M., Fallow, P. M., \& Radford, A. N. (2014). Eavesdropping on heterospecific alarm calls: From mechanisms to consequences. Biological Reviews, 90, 1-27.

Magrath, R. D., Pitcher, B. J., \& Gardner, J. L. (2009). An avian eavesdropping network: Alarm signal reliability and heterospecific response. Behavioral Ecology, 20, 745-752.

Mammides, C., Chen, J., Goodale, U. M., Kotagama, S. W., \& Goodale, E. (2018). Measurement of species associations in mixed-species bird flocks across environmental and human disturbance gradients. Ecosphere, 9, e02324-14.

Marler, P. (1955). Characteristics of some animal calls. Nature, 176, 6-8.

Marler, P. (1957). Specific distinctiveness in the communication signals of birds. Behaviour, 11, 13-39.

Masco, C., Allesina, S., Mennill, D. J., \& Pruett-Jones, S. (2015). The song overlap null model generator (SONG): A new tool for distinguishing between random and non-random song overlap. Bioacoustics - the International Journal of Animal Sound and Its Recording, 25, 29-40.

McLachlan, J. R., Ratnayake, C. P., \& Magrath, R. D. (2019). Personal information about danger trumps social information from avian alarm calls. Proceedings of the Royal Society B: Biological Sciences, 286, $20182945-9$.

Millon, A., Nielsen, J. T., Bretagnolle, V., \& Møller, A. P. (2009). Predator-prey relationships in a changing environment: The case of the sparrowhawk and its avian prey community in a rural area. Journal of Animal Ecology, 78, 1086-1095.

Morse, D. H. (1973). Interactions between tit flocks and sparrowhawks Accipiter nisus. Ibis, 115, 591-593.

Moynihan, M. (1962). The organization and probable evolution of some mixed species flocks of neotropical birds. Smithsonian Miscellaneous Collections, 143, 1-143.

Munoz, N., Brandstetter, G., Esgro, L., Greene, W., \& Blumstein, D. T. (2015). Asymmetric eavesdropping between common mynas and red-vented bulbuls. Behavioral Ecology, 26, 689-696.

Murphy, D., Lea, S. E. G., \& Zuberbühler, K. (2013). Male blue monkey alarm calls encode predator type and distance. Animal Behaviour, 85, 119-125.

Murray, T. G., \& Magrath, R. D. (2015). Does signal deterioration compromise eavesdropping on other species' alarm calls? Animal Behaviour, 108, 33-41.

Newton, I. (1986). The Sparrowhawk (1st ed.). T. \& A. D. Poyser Ltd.

Nolen, M. T., \& Lucas, J. R. (2009). Asymmetries in mobbing behaviour and correlated intensity during predator mobbing by nuthatches, chickadees and titmice. Animal Behaviour, 77, 1137-1146.

Pagani-Núñez, E., Xia, X., Beauchamp, G., He, R., Husson, J. H. D., Liang, D., \& Goodale, E. (2018). Are vocal characteristics related to leadership patterns in mixed-species bird flocks? Journal of Avian Biology, 49, jav-01674. 
Perrins, C. M., Davies, M., Gilmour, J., Mellanby, K. \& Hosking. E. (1979). British Tits (1st ed.). William Collins Sons \& Co. Ltd.

Petty, S. J., Patterson, I. J., Anderson, D. I. K., Little, B., \& Davison, M. (1995). Numbers, breeding performance, and diet of the sparrowhawk Accipiter nisus and merlin Falco columbarius in relation to cone crops and seed-eating finches. Forest Ecology and Management, 79, 133-146.

Placer, J., \& Slobodchikoff, C. N. (2000). A fuzzy-neural system for identification of species-specific alarm calls of Gunnison's prairie dogs. Behavioural Processes, 52, 1-9.

Placer, J., \& Slobodchikoff, C. N. (2004). A method for identifying sounds used in the classification of alarm calls. Behavioural Processes, 67, 87-98.

R Core Team. (2014). R: A language and environment for statistical computing (3rd ed.). Vienna, Austria: R Foundation for Statistical Computing. Retrieved from http://www.R-project.org/

Rainey, H. J., Zuberbühler, K., \& Slater, P. J. B. (2004a). Hornbills can distinguish between primate alarm calls. Proceedings of the Royal Society of London, 271, 755-759.

Rainey, H. J., Zuberbühler, K., \& Slater, P. J. B. (2004b). The responses of black-casqued hornbills to predator vocalisations and primate alarm calls. Behaviour, 141, 1263-1277.

Randler, C. (2012). A possible phylogenetically conserved urgency response of great tits (Parus major) towards allopatric mobbing calls. Behavioral Ecology and Sociobiology, 66, 675-681.

Randler, C., \& Förschler, M. I. (2011). Heterospecifics do not respond to subtle differences in chaffinch mobbing calls: Message is encoded in number of elements. Animal Behaviour, 82, 725-730.

Randler, C., \& Vollmer, C. (2013). Asymmetries in commitment in an avian communication network. Naturwissenschaften, 100, 199-203.

Ridley, A. R., Child, M. F., \& Bell, M. B. V. (2007). Interspecific audience effects on the alarm-calling behaviour of a kleptoparasitic bird. Biology Letters, 3, 589-591.

Ridley, A. R., Wiley, E. M., \& Thompson, A. M. (2013). The ecological benefits of interceptive eavesdropping. Functional Ecology, 28, 197-205.

Rieucau, G., \& Giraldeau, L.-A. (2011). Exploring the costs and benefits of social information use: An appraisal of current experimental evidence. Philosophical Transactions of the Royal Society B-Biological Sciences, 366, 949-957.

Schmidt, K. A., Dall, S. R. X., \& van Gils, J. A. (2010). The ecology of information: An overview on the ecological significance of making informed decisions. Oikos, 119, 304-316.

Seoraj-Pillai, N., \& Malan, G. (2014). Characteristics of the alarm calls of buff-streaked chat groups and African stonechat pairs in response to increased distances from surrogate raptors and snakes. African Zoology, 49, 137-147.

Sherman, P. W. (1977). Nepotism and the evolution of alarm calls. Science, 179, 1246-1253.

Sherman, P. W. (1985). Alarm calls of Belding's ground squirrels to aerial predators: Nepotism or self-preservation? Behavioural Ecology and Sociobiology, 17, 313-323.

Shriner, W. M. (1998). Yellow-bellied marmot and golden-mantled ground squirrel responses to heterospecific alarm calls. Animal Behaviour, 55, 529-536.

Soard, C. M., \& Ritchison, G. (2009). Chick-a-dee calls of Carolina chickadees convey information about degree of threat posed by avian predators. Animal Behaviour, 78, 1447-1453.

Srinivasan, U., Raza, R. H., \& Quader, S. (2010). The nuclear question: Rethinking species importance in multispecies animal groups. Journal of Animal Ecology, 79, 948-954.

Sullivan, K. A. (1985). Selective alarm calling by downy woodpeckers in mixed-species flocks. The Auk, 102, 184187.

Sullivan, K. A. (1994). Information exploitation by downy woodpeckers in mixed-species flocks. Behaviour, 91, 294-311.

Suzuki, T. N. (2014). Communication about predator type by a bird using discrete, graded and combinatorial variation in alarm calls. Animal Behaviour, 87, 59-65.

Suzuki, T. N. (2016). Referential calls coordinate multi-species mobbing in a forest bird community. Journal of Ethology, 34, 79-84.

Suzuki, T. N. (2018). Alarm calls evoke a visual search image of a predator in birds. Proceedings of the National Academy of Sciences of the United States of America, 115, 1541-1545.

Suzuki, T. N., \& Kutsukake, N., (2017). Foraging intention affects whether willow tits call to attract members of mixed-species flocks. Royal Society Open Science, 4, 170222.

Swann, R. L., \& Etheridge, B. (2009). A comparison of breeding success and prey of the common buzzard Buteo buteo in two areas of northern Scotland. Bird Study, 42, 37-43. 
Šálek, M., Marhoul, P., Pintír, J., Kopecký, T., \& Slabý, L. (2004). Importance of unmanaged wasteland patches for the grey partridge Perdix perdix in suburban habitats. Acta Oecologica - International Journal of Ecology, $25,23-33$.

Templeton, C. N., \& Greene, E. (2007). Nuthatches eavesdrop on variations in heterospecific chickadee mobbing alarm calls. Proceedings of the National Academy of Sciences of the United States of America, 104, 54795482 .

Templeton, C. N., Greene, E., \& Davis, K. (2005). Allometry of alarm calls: Black-capped chickadees encode information about predator size. Science, 308, 1934-1937.

Templeton, C. N., Zollinger, S. A., \& Brumm, H. (2016). Traffic noise drowns out great tit alarm calls. Current Biology, 26, R1173-R1174.

Townsend, S. W., \& Manser, M. B. (2013). Functionally referential communication in mammals: The past, present and the future. Ethology, 119, 1-11.

Townsend, S. W., Rasmussen, M., Clutton-Brock, T., \& Manser, M. B. (2012). Flexible alarm calling in meerkats: The role of the social environment and predation urgency. Behavioral Ecology, 23, 1360-1364.

Welbergen, J. A., \& Davies, N. B. (2008). Reed warblers discriminate cuckoos from sparrowhawks with graded alarm signals that attract mates and neighbours. Animal Behaviour, 76, 811-822.

Wich, S. A., \& Sterck, E. H. M. (2003). Possible audience effect in Thomas langurs (primates; Presbytis thomasi): An experimental study on male loud calls in response to a tiger model. American Journal of Primatology, $60,155-159$.

Wiley, R. H. (2009). Signal transmission in natural environments. New Encyclopedia of Neuroscience, 8, 827-832.

Woods, R. D., Kings, M., McIvor, G. E., \& Thornton, A. (2018). Caller characteristics influence recruitment to collective anti- predator events in jackdaws. Scientific Reports, 8, 1-8.

Zawadzka, D., \& Zawadzki, J. (2001). Breeding populations and diets of the sparrowhawk Accipiter nisus and the hobby Falco subbuteo in the Wigry National Park (Ne Poland). Acta Ornithologica, 36, 25-31.

Zhou, Y., Radford, A. N., \& Magrath, R. D. (2019). Why does noise reduce response to alarm calls? Experimental assessment of masking, distraction and greater vigilance in wild birds. Functional Ecology, 33, 1280-1289. 


\section{Appendix}

\section{Table A1}

Test Results for Generalized and Linear Mixed Models Testing for Predator Type, Group Size (Conspecific and Flock Size) and Composition (Presence of Blue, Great, and Coal Tits) on Ways of Encoding Information about Predator Threat for Blue Tits $\$$ Indicates the Model Residuals were not Normally Distributed, L and Bc Indicate that Data was Log $(L)$ or Box-Cox $(B c)$ Transformed if Residuals were not Normal for Linear Mixed Models. Bonferroni Corrected P-Values Based on the Number of Models are .005. In the Case of Significant Lower Order Effects Without Higher Order Interactions, + and - to the Right of the P-Value Indicate Whether the Effect is Positive or Negative, Respectively.

\begin{tabular}{|c|c|c|c|c|c|c|c|c|c|c|c|c|}
\hline $\begin{array}{l}\text { Encoding Method } \\
\text { Call/element type }\end{array}$ & Factors & $\chi^{2}$ & $\mathrm{df}$ & $p$ & $\begin{array}{l}\text { Call/element Type } \\
\text { Factors }\end{array}$ & $\chi^{2}$ & $\mathrm{df}$ & $p$ & $\begin{array}{l}\text { Call/element Type } \\
\text { Factors }\end{array}$ & $\chi^{2}$ & df & $p$ \\
\hline \multirow{13}{*}{$\begin{array}{l}\text { Propensity to use } \\
\text { Rate (1) }\end{array}$} & & & & & Call & & & & & & & \\
\hline & Intercept & 17.72 & 1 & $<.001$ & Intercept & 0.01 & 1 & .933 & & & & \\
\hline & Stimulus & 28.89 & 2 & $<.001$ & Stimulus & 34.56 & 2 & $<.001$ & & & & \\
\hline & Order & 0.23 & 2 & .892 & Order & 0.07 & 2 & .966 & & & & \\
\hline & Mount exemplar & 3.06 & 1 & .080 & Mount exemplar & 0.01 & 1 & .944 & & & & \\
\hline & No. blue tits & 8.41 & 1 & .004 & No. blue tits & 5.23 & 1 & .022 & & & & \\
\hline & Great tits present & 5.27 & 1 & .022 & Great tits present & 0.05 & 1 & .825 & & & & \\
\hline & Coal tits present & 0.01 & 1 & .914 & Coal tits present & 0.56 & 1 & .453 & & & & \\
\hline & Stimulus: Order & 2.87 & 4 & .580 & Stimulus: Order & 4.76 & 4 & .313 & & & & \\
\hline & Stimulus: Mount exemplar & 3.76 & 2 & .153 & Stimulus: Mount exemplar & 9.57 & 2 & .008 & & & & \\
\hline & Stimulus: No. blue tits & 8.80 & 2 & .012 & Stimulus: No. blue tits & 1.19 & 2 & .551 & & & & \\
\hline & Stimulus: Great tits present & 3.35 & 2 & .187 & Stimulus: Great tits present & 2.50 & 2 & .286 & & & & \\
\hline & Stimulus: Coal tits present & 3.98 & 2 & .137 & Stimulus: Coal tits present & 4.73 & 2 & .094 & & & & \\
\hline \multirow{13}{*}{$\begin{array}{l}\text { Number of } \\
\text { Total elements }\end{array}$} & & & & & Mid elements & & & & D elements (bc) & & & \\
\hline & Intercept & 29.00 & 1 & $<.001$ & Intercept & 2.56 & 1 & .110 & Intercept & 386.61 & 1 & $<.001$ \\
\hline & Stimulus & 4.89 & 2 & .087 & Stimulus & 3.84 & 2 & .146 & Stimulus & 2.03 & 2 & .362 \\
\hline & Order & 1.60 & 2 & .449 & Order & 2.69 & 2 & .260 & Order & 0.35 & 2 & .838 \\
\hline & Mount exemplar & 0.76 & 1 & .385 & Mount exemplar & 3.40 & 1 & .065 & Mount exemplar & 0.00 & 1 & .952 \\
\hline & No. blue tits & 0.92 & 1 & .338 & No. blue tits & 0.09 & 1 & .760 & No. blue tits & 17.31 & 1 & $<.001$ \\
\hline & Great tits present & 7.04 & 1 & $.008+$ & Great tits present & 2.77 & 1 & .096 & Great tits present & 17.02 & 1 & $<.001$ \\
\hline & Coal tits present & 5.28 & 1 & $.022-$ & Coal tits present & 3.00 & 1 & .083 & Coal tits present & 19.44 & 1 & $<.001$ \\
\hline & Stimulus: Order & 16.68 & 4 & .002 & Stimulus: Order & 9.16 & 3 & .027 & Stimulus: Order & 8.68 & 4 & .070 \\
\hline & Stimulus: Mount exemplar & 6.20 & 2 & .045 & Stimulus: Mount exemplar & 1.42 & 1 & .233 & Stimulus: Mount exemplar & 1.53 & 2 & .466 \\
\hline & Stimulus: No. blue tits & 3.68 & 2 & .159 & Stimulus: No. blue tits & 2.78 & 2 & .249 & Stimulus: No. blue tits & 22.11 & 2 & $<.001$ \\
\hline & Stimulus: Great tits present & 5.50 & 2 & .064 & Stimulus: Great tits present & 2.32 & 1 & .128 & Stimulus: Great tits present & 7.49 & 2 & .024 \\
\hline & Stimulus: Coal tits present & 2.18 & 2 & .336 & Stimulus: Coal tits present & 2.54 & 1 & .111 & Stimulus: Coal tits present & 20.37 & 2 & $<.001$ \\
\hline
\end{tabular}


Table Al cont.

\begin{tabular}{|c|c|c|c|c|c|c|c|c|c|c|c|c|}
\hline \multirow[b]{2}{*}{$\begin{array}{l}\text { Proportion of } \\
\text { Exit calls }(1, \S)\end{array}$} & \multirow[b]{2}{*}{ Intercept } & \multirow[b]{2}{*}{0.06} & \multirow[b]{2}{*}{1} & \multirow[b]{2}{*}{.813} & \multicolumn{4}{|l|}{ Chirp calls } & \multicolumn{4}{|l|}{ Tonal calls } \\
\hline & & & & & Intercept & 1.89 & 1 & .169 & Intercept & 18.11 & 1 & $<.001$ \\
\hline & Stimulus & 24.49 & 2 & $<.001$ & Stimulus & 34.34 & 2 & $<.001$ & Stimulus & 11.32 & 2 & .003 \\
\hline & Order & 0.62 & 2 & .733 & Order & 6.50 & 2 & .039 & Order & 5.48 & 2 & .064 \\
\hline & Mount exemplar & 12.46 & 1 & $<.001$ & Mount exemplar & 11.45 & 1 & .001 & Mount exemplar & 0.00 & 1 & .977 \\
\hline & No. blue tits & 2.35 & 1 & .126 & No. blue tits & 8.53 & 1 & .004 & No. blue tits & 8.34 & 1 & $.004+$ \\
\hline & Great tits present & 2.57 & 1 & .109 & Great tits present & 4.75 & 1 & .029 & Great tits present & 1.35 & 1 & .246 \\
\hline & Coal tits present & 0.16 & 1 & .694 & Coal tits present & 0.38 & 1 & .535 & Coal tits present & 2.82 & 1 & .093 \\
\hline & Stimulus: Order & 7.15 & 4 & .128 & Stimulus: Order & 27.86 & 4 & $<.001$ & Stimulus: Order & 22.18 & 4 & $<.001$ \\
\hline & Stimulus: Mount exemplar & 17.43 & 2 & $<.001$ & Stimulus: Mount exemplar & 18.12 & 2 & $<.001$ & Stimulus: Mount exemplar & 1.94 & 2 & .379 \\
\hline & Stimulus: No. blue tits & 12.50 & 2 & .002 & Stimulus: No. blue tits & 12.71 & 2 & .002 & Stimulus: No. blue tits & 4.62 & 2 & .099 \\
\hline & Stimulus: Great tits present & 2.96 & 2 & .227 & Stimulus: Great tits present & 11.60 & 2 & .003 & Stimulus: Great tits present & 5.55 & 2 & .062 \\
\hline & Stimulus: Coal tits present & 15.57 & 2 & $<.001$ & Stimulus: Coal tits present & 2.33 & 2 & .311 & Stimulus: Coal tits present & 2.97 & 2 & .226 \\
\hline & & & & & Exit elements (l) & & & & Tonal calls & & & \\
\hline \multirow[t]{13}{*}{$\begin{array}{l}\text { Propensity to use } \\
\text { Mid elements (1) }\end{array}$} & Intercept & 0.28 & 1 & .598 & Intercept & 0.02 & 1 & .893 & Intercept & 5.39 & 1 & .020 \\
\hline & Stimulus & 27.70 & 2 & $<.001$ & Stimulus & 17.44 & 2 & $<.001$ & Stimulus & 4.49 & 2 & .106 \\
\hline & Order & 1.88 & 2 & .391 & Order & 0.38 & 2 & .827 & Order & 0.91 & 2 & .634 \\
\hline & Mount exemplar & 0.03 & 1 & .870 & Mount exemplar & 6.98 & 1 & .008 & Mount exemplar & 0.07 & 1 & .798 \\
\hline & No. blue tits & 2.36 & 1 & .124 & No. blue tits & 4.84 & 1 & $.028+$ & No. blue tits & 5.24 & 1 & $.022+$ \\
\hline & Great tits present & 0.59 & 1 & .441 & Great tits present & 8.31 & 1 & .004 & Great tits present & 0.06 & 1 & .808 \\
\hline & Coal tits present & 0.17 & 1 & .676 & Coal tits present & 0.04 & 1 & .850 & Coal tits present & 0.85 & 1 & .355 \\
\hline & Stimulus: Order & 11.17 & 4 & .025 & Stimulus: Order & 4.36 & 4 & .360 & Stimulus: Order & 6.09 & 4 & .192 \\
\hline & Stimulus: Mount exemplar & 11.94 & 2 & .003 & Stimulus: Mount exemplar & 9.08 & 2 & .011 & Stimulus: Mount exemplar & 0.15 & 2 & .927 \\
\hline & stimulus: No. blue tits & 1.47 & 2 & .480 & Stimulus: No. blue tits & 3.24 & 2 & .198 & Stimulus: No. blue tits & 2.84 & 2 & .242 \\
\hline & Stimulus: Great tits present & 1.66 & 2 & .436 & Stimulus: Great tits present & 6.54 & 2 & .038 & Stimulus: Great tits present & 1.57 & 2 & .456 \\
\hline & Stimulus: Coal tits present & 0.60 & 2 & .742 & Stimulus: Coal tits present & 1.32 & 2 & .517 & Stimulus: Coal tits present & 3.11 & 2 & .211 \\
\hline & & & & & Short calls (l) & & & & & & & \\
\hline
\end{tabular}


Carlson et al. 235

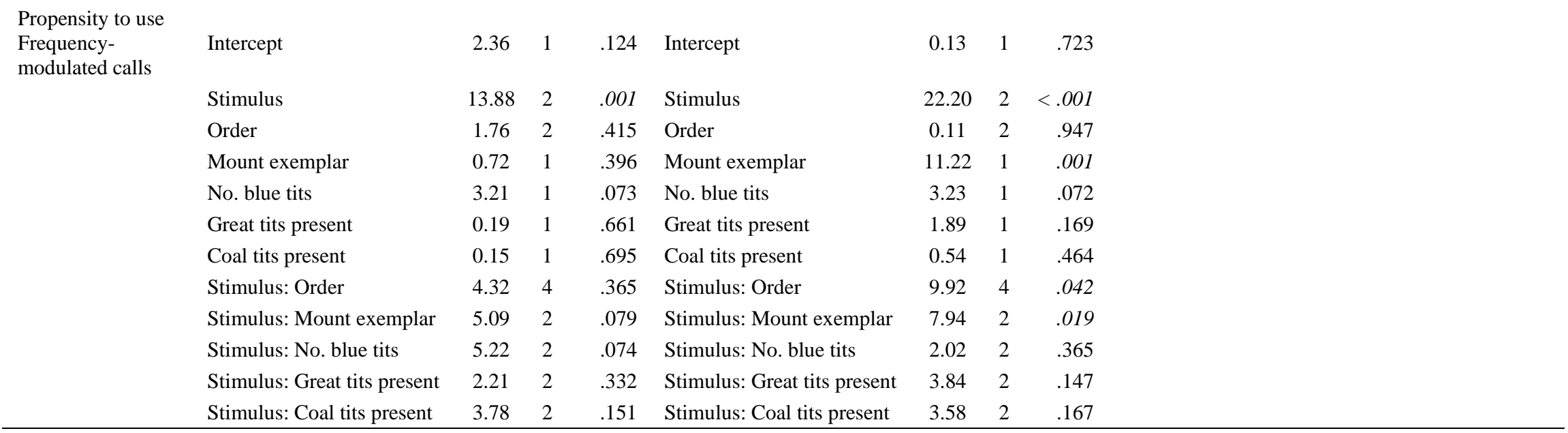


Carlson et al. 236

Table A2

Test Results for Generalized and Linear Mixed Models Testing for Predator Type, Group Size (Conspecific and Flock Size) and Composition (Presence of Blue, Great, and Coal Tits) on Ways of Encoding Information about Predator Threat for Great Tits. Bonferroni Corrected P-Values Based on the Number of Models are .017.

\begin{tabular}{|c|c|c|c|c|c|c|c|c|}
\hline $\begin{array}{l}\text { Encoding Method } \\
\text { Call/element type }\end{array}$ & Factors & $\chi^{2}$ & $\mathrm{df}$ & $p$ & $\begin{array}{l}\text { Call/element type } \\
\text { Factors }\end{array}$ & $\chi^{2}$ & df & $p$ \\
\hline & & & & & Call & & & \\
\hline \multirow{12}{*}{$\begin{array}{l}\text { Propensity to use } \\
\text { Rate }\end{array}$} & Intercept & 5.68 & 1 & .017 & Intercept & 0.61 & 1 & .435 \\
\hline & Stimulus & 6.23 & 2 & .044 & Stimulus & 5.74 & 2 & .057 \\
\hline & Order & 2.95 & 2 & .229 & Order & 0.09 & 2 & .957 \\
\hline & Mount exemplar & 0.55 & 1 & .459 & Mount exemplar & 0.00 & 1 & .973 \\
\hline & No. great tits & 0.85 & 1 & .358 & No. great tits & 0.00 & 1 & .971 \\
\hline & Blue tits present & 0.69 & 1 & .406 & Blue tits present & 0.14 & 1 & .705 \\
\hline & Coal tits present & 0.10 & 1 & .758 & Coal tits present & 0.01 & 1 & .903 \\
\hline & Stimulus: Order & 8.47 & 4 & .076 & Stimulus: Order & 3.12 & 4 & .538 \\
\hline & Stimulus: Mount exemplar & 2.98 & 2 & .226 & Stimulus: Mount exemplar & 1.33 & 2 & .514 \\
\hline & Stimulus: No. great tits & 1.83 & 2 & .401 & Stimulus: No. great tits & 6.91 & 2 & .032 \\
\hline & Stimulus: Blue tits present & 3.79 & 2 & .150 & Stimulus: Blue tits present & 0.39 & 2 & .824 \\
\hline & Stimulus: Coal tits present & 0.22 & 2 & .895 & Stimulus: Coal tits present & 0.03 & 2 & .986 \\
\hline \multirow[t]{12}{*}{$\begin{array}{l}\text { Proportion of } \\
\text { Chirp calls }\end{array}$} & Intercept & 7.53 & 1 & .006 & & & & \\
\hline & Stimulus & 16.20 & 2 & $<.001$ & & & & \\
\hline & Order & 83.07 & 2 & $<.001$ & & & & \\
\hline & Mount exemplar & 40.47 & 1 & $<.001$ & & & & \\
\hline & No. great tits & 39.83 & 1 & $<.001$ & & & & \\
\hline & Blue tits present & 0.35 & 1 & .552 & & & & \\
\hline & Coal tits present & 33.05 & 1 & $<.001$ & & & & \\
\hline & Stimulus: Order & 54.76 & 4 & $<.001$ & & & & \\
\hline & Stimulus: Mount exemplar & 60.86 & 2 & $<.001$ & & & & \\
\hline & Stimulus: No. great tits & 15.75 & 2 & $<.001$ & & & & \\
\hline & Stimulus: Blue tits present & 2.99 & 2 & .224 & & & & \\
\hline & Stimulus: Coal tits present & 24.89 & 2 & $<.001$ & & & & \\
\hline
\end{tabular}

Table A2 cont. 
Carlson et al. 237

\begin{tabular}{lllll}
$\begin{array}{l}\text { Propensity to use } \\
\text { Jar/rattle calls }\end{array}$ & Intercept & 5.43 & 1 & .020 \\
Stimulus & & 2.66 & 2 & .264 \\
Order & 1.44 & 2 & .488 \\
Mount exemplar & 1.84 & 1 & .175 \\
No. great tits & 0.06 & 1 & .805 \\
Blue tits present & 0.30 & 1 & .586 \\
Coal tits present & 0.03 & 1 & .858 \\
Stimulus: Order & 3.09 & 4 & .543 \\
Stimulus: Mount exemplar & 2.44 & 2 & .295 \\
Stimulus: No. great tits & 0.11 & 2 & .948 \\
Stimulus: Blue tits present & 0.63 & 2 & .731 \\
Stimulus: Coal tits present & 0.09 & 2 & .955 \\
\hline
\end{tabular}




\section{Table A3}

Test Results for Generalized and Linear Mixed Models Testing for Predator Type, Group Size (Conspecific and Flock Size) and Composition (Presence of Blue, Great, and Coal Tits) on Ways of Encoding Information about Predator Threat for Coal Tits. L And Bc Indicate that Data was Log (L) Or Box-Cox (Bc) Transformed if Residuals were not Normal for Linear Mixed Models. Bonferroni Corrected P-Values Based on the Number of Models are .006.

\begin{tabular}{|c|c|c|c|c|c|c|c|c|c|c|c|c|}
\hline $\begin{array}{l}\text { Encoding Method } \\
\text { Call/element type }\end{array}$ & Factors & $\chi^{2}$ & $\mathrm{df}$ & $p$ & $\begin{array}{l}\text { Call/element type } \\
\text { Factors }\end{array}$ & $\chi^{2}$ & df & $p$ & $\begin{array}{l}\text { Call/element type } \\
\text { Factors }\end{array}$ & $\chi^{2}$ & df & $p$ \\
\hline & & & & & Call & & & & & & & \\
\hline \multirow{13}{*}{$\begin{array}{l}\text { Propensity to use } \\
\text { Rate }\end{array}$} & Intercept & 0.01 & 1 & .904 & Intercept & 0.07 & 1 & .786 & & & & \\
\hline & Stimulus & 20.64 & 2 & $<.001$ & Stimulus & 16.99 & 2 & $<.001$ & & & & \\
\hline & Order & 0.19 & 2 & .910 & Order & 0.32 & 2 & .853 & & & & \\
\hline & Mount exemplar & 0.33 & 1 & .565 & Mount exemplar & 0.05 & 1 & .819 & & & & \\
\hline & No. coal tits & 0.03 & 1 & .862 & No. coal tits & 0.85 & 1 & .357 & & & & \\
\hline & Blue tits present & 1.19 & 1 & .275 & Blue tits present & 1.12 & 1 & .290 & & & & \\
\hline & Great tits present & 0.07 & 1 & .797 & Great tits present & 0.06 & 1 & .803 & & & & \\
\hline & Stimulus: Order & 2.66 & 4 & .617 & Stimulus: Order & 7.22 & 4 & .125 & & & & \\
\hline & $\begin{array}{l}\text { Stimulus: Mount } \\
\text { exemplar }\end{array}$ & 4.06 & 2 & .131 & $\begin{array}{l}\text { Stimulus: Mount } \\
\text { exemplar }\end{array}$ & 5.64 & 2 & .060 & & & & \\
\hline & Stimulus: No. coal tits & 1.83 & 2 & .400 & Stimulus: No. coal tits & 3.00 & 2 & .223 & & & & \\
\hline & $\begin{array}{l}\text { Stimulus: Blue tits } \\
\text { present }\end{array}$ & 5.66 & 2 & .059 & $\begin{array}{l}\text { Stimulus: Blue tits } \\
\text { present }\end{array}$ & 6.14 & 2 & .046 & & & & \\
\hline & $\begin{array}{l}\text { Stimulus: Great tits } \\
\text { present }\end{array}$ & 1.93 & 2 & .381 & $\begin{array}{l}\text { Stimulus: Great tits } \\
\text { present }\end{array}$ & 0.03 & 2 & .986 & & & & \\
\hline & & & & & Mound elements (l) & & & & Mt elements & & & \\
\hline \multirow[t]{7}{*}{$\begin{array}{l}\text { Number of } \\
\text { Hook elements (1) }\end{array}$} & Intercept & 0.01 & 1 & .909 & Intercept & 0.33 & 1 & .568 & Intercept & 1.20 & 1 & .273 \\
\hline & Stimulus & 16.22 & 2 & $<.001$ & Stimulus & 5.87 & 2 & .053 & Stimulus & 13.48 & 2 & .001 \\
\hline & Order & 2.62 & 2 & .270 & Order & 0.22 & 2 & .898 & Order & 0.05 & 2 & .977 \\
\hline & Mount exemplar & 0.74 & 1 & .388 & Mount exemplar & 0.96 & 1 & .327 & Mount exemplar & 0.18 & 1 & .671 \\
\hline & No. coal tits & 0.17 & 1 & .677 & No. coal tits & 0.23 & 1 & .634 & No. coal tits & 0.05 & 1 & .823 \\
\hline & Blue tits present & 1.17 & 1 & .279 & Blue tits present & 2.42 & 1 & .119 & Blue tits present & 0.13 & 1 & .722 \\
\hline & Great tits present & 0.74 & 1 & .389 & Great tits present & 9.89 & 1 & .002 & Great tits present & 0.02 & 1 & .897 \\
\hline \multicolumn{12}{|l|}{ Table A3 cont. } & .528 \\
\hline
\end{tabular}


Stimulus: Mount

exemplar

Stimulus: No. coal tits

Stimulus: Blue tits

present

Stimulus: Great tits

present

Number of

S-dot elements (1)

Intercept

Stimulus

Order

Mount exemplar

No. coal tits

Blue tits present

Great tits present

Stimulus: Order

Stimulus: Mount

exemplar

Stimulus: No. coal tit

Stimulus: Blue tits

present

Stimulus: Great tits

present

Propensity to use

Mound elements

(1)

Table A3 cont

Intercept

Stimulus

Order

Mount exemplar

No. coal tits

Blue tits present

Great tits presen

Stimulus: Order

Stimulus: Mount
Stimulus: Mount

exemplar

Stimulus: No. coal tits

Stimulus: Blue tits

present

Stimulus: Great tits

present

\section{Squeak elements (bc)}

\begin{tabular}{|c|c|c|c|}
\hline 16.01 & 1 & $<.001$ & Intercept \\
\hline 3.81 & 2 & .149 & Stimulus \\
\hline 0.76 & 2 & .685 & Order \\
\hline 9.51 & 1 & .002 & Mount exemplar \\
\hline 4.96 & 1 & .026 & No. coal tits \\
\hline 3.38 & 1 & .066 & Blue tits present \\
\hline 4.91 & 1 & .027 & Great tits present \\
\hline 2.16 & 4 & .706 & Stimulus: Order \\
\hline 1.29 & 1 & .256 & $\begin{array}{l}\text { Stimulus: Mount } \\
\text { exemplar }\end{array}$ \\
\hline 4.80 & 2 & .091 & Stimulus: No. coal tits \\
\hline 2.72 & 2 & .256 & $\begin{array}{l}\text { Stimulus: Blue tits } \\
\text { present }\end{array}$ \\
\hline 6.42 & 2 & .040 & $\begin{array}{l}\text { Stimulus: Great tits } \\
\text { present }\end{array}$ \\
\hline
\end{tabular}

Squeak elements (I)

$\begin{array}{llll}0.17 & 1 & .681 & \text { Intercept } \\ & & & \\ 6.19 & 2 & .045 & \text { Stimulus } \\ 1.45 & 2 & .485 & \text { Order } \\ 0.10 & 1 & .750 & \text { Mount exemplar } \\ 0.67 & 1 & .413 & \text { No. coal tits } \\ 2.64 & 1 & .104 & \text { Blue tits present } \\ 0.53 & 1 & .466 & \text { Great tits present } \\ & & & \\ 4.87 & 4 & .301 & \text { Stimulus: Order } \\ 0.80 & 2 & .672 & \text { Stimulus: Mount }\end{array}$

Stimulus: Mount

exemplar

Stimulus: No. coal tits

Stimulus: Blue tits

present

$\begin{array}{lll}5.70 \quad 1 & .017\end{array}$

Stimulus: Great tits

present $\begin{array}{lll}5.45 & 1 & .020\end{array}$

$\begin{array}{lll}1.11 & 2 & .573\end{array}$

$\begin{array}{lll}1.09 & 2 & .58\end{array}$

$\begin{array}{lll}0.80 & 2 & .672\end{array}$

$\begin{array}{lll}3.60 & 1 & .058 \\ 2.13 & 2 & .345 \\ 7.98 & 2 & .019 \\ 0.71 & 1 & .401 \\ 0.00 & 1 & .000 \\ 0.03 & 1 & .866 \\ 2.72 & 1 & .099 \\ 10.41 & 4 & .034 \\ 0.99 & 1 & .320 \\ 0.28 & 2 & .867 \\ 1.01 & 2 & .605 \\ 0.10 & 1 & .749\end{array}$

$\begin{array}{lll}0.79 & 1 & .374\end{array}$

$\begin{array}{lll}8.40 \quad 2 & .015\end{array}$

$\begin{array}{lll}2.06 & 2 & .357\end{array}$

$\begin{array}{lll}1.66 & 1 & .197\end{array}$

$\begin{array}{lll}0.27 & 1 & .600\end{array}$

$\begin{array}{lll}0.11 & 1 & .744\end{array}$

$0.00 \quad 1 \quad .962$

$\begin{array}{lll}7.87 \quad 4 & .096\end{array}$

$\begin{array}{lll}0.48 & 2 & .785\end{array}$ 
Carlson et al. 240

\begin{tabular}{|c|c|c|c|c|c|c|c|}
\hline exemplar & & & & exemplar & & & \\
\hline Stimulus: No. coal tits & 0.20 & 2 & .906 & Stimulus: No. coal tits & 2.92 & 2 & .233 \\
\hline $\begin{array}{l}\text { Stimulus: Blue tits } \\
\text { present }\end{array}$ & 4.43 & 2 & .109 & $\begin{array}{l}\text { Stimulus: Blue tits } \\
\text { present }\end{array}$ & 5.42 & 2 & .066 \\
\hline $\begin{array}{l}\text { Stimulus: Great tits } \\
\text { present }\end{array}$ & 2.50 & 2 & .287 & $\begin{array}{l}\text { Stimulus: Great tits } \\
\text { present }\end{array}$ & 2.01 & 2 & .367 \\
\hline
\end{tabular}




\section{Table A4}

Test Results for Generalized and Linear Mixed Models Testing for Predator Type, Group Size (Conspecific and Flock Size) and Composition (Presence of Blue, Great, and Coal Tits) on Ways of Encoding Information About Predator Threat for Crested Tits. L Indicates that Data was Log (L) Transformed if Residuals were not Normal for Linear Mixed Models. Bonferroni Corrected P-Values Based on the Number of Models are .017. In the Case of Significant Lower Order Effects Without Higher Order Interactions, + and - to the Right of the P-Value Indicate Whether the Effect is Positive or Negative, Respectively.

\begin{tabular}{|c|c|c|c|c|c|c|c|c|}
\hline $\begin{array}{l}\text { Encoding Method } \\
\text { Call/element type }\end{array}$ & Factors & $\chi^{2}$ & $\mathrm{df}$ & $p$ & $\begin{array}{l}\text { Call/element type } \\
\text { Factors }\end{array}$ & $\chi^{2}$ & $\mathrm{df}$ & $p$ \\
\hline & & & & & Call (l) & & & \\
\hline \multirow[t]{14}{*}{$\begin{array}{l}\text { Propensity to use } \\
\text { Rate (l) }\end{array}$} & Intercept & 2.99 & 1 & .084 & Intercept & 2.18 & 1 & .140 \\
\hline & Stimulus & 1.67 & 2 & .434 & Stimulus & 2.05 & 2 & .358 \\
\hline & Order & 1.22 & 2 & .542 & Order & 1.48 & 2 & .478 \\
\hline & Mount exemplar & 5.78 & 1 & .016 & Mount exemplar & 7.35 & 1 & .007 \\
\hline & No. crested tits & 0.36 & 1 & .548 & No. crested tits & 0.14 & 1 & .706 \\
\hline & Blue tits present & 9.80 & 1 & $.002-$ & Blue tits present & 11.35 & 1 & $.001-$ \\
\hline & Great tits present & 0.80 & 1 & .371 & Great tits present & 0.79 & 1 & .373 \\
\hline & Flock size & 4.50 & 1 & $.034+$ & Flock size & 6.34 & 1 & .012 \\
\hline & Stimulus: Order & 2.34 & 4 & .674 & Stimulus: Order & 2.56 & 4 & .633 \\
\hline & Stimulus: Mount exemplar & 5.14 & 2 & .077 & Stimulus: Mount exemplar & 6.43 & 2 & .040 \\
\hline & Stimulus: No. crested tits & 1.32 & 2 & .516 & Stimulus: No. crested tits & 1.38 & 2 & .501 \\
\hline & Stimulus: Blue tits present & 3.70 & 2 & .157 & Stimulus: Blue tits present & 4.15 & 2 & .125 \\
\hline & Stimulus: Great tits present & 1.42 & 2 & .491 & Stimulus: Great tits present & 1.65 & 2 & .438 \\
\hline & Stimulus: Flock size & 5.16 & 2 & .076 & Stimulus: Flock size & 6.02 & 2 & .049 \\
\hline \multirow[t]{10}{*}{$\begin{array}{l}\text { Proportion of } \\
\text { Frequency-modulated }\end{array}$} & Intercept & 1.47 & 1 & .226 & & & & \\
\hline & Stimulus & 31.74 & 2 & $<.001$ & & & & \\
\hline & Order & 1.21 & 2 & .546 & & & & \\
\hline & Mount exemplar & 0.13 & 1 & .721 & & & & \\
\hline & No. crested tits & 0.02 & 1 & .895 & & & & \\
\hline & Blue tits present & 6.68 & 1 & .010 & & & & \\
\hline & Great tits present & 3.77 & 1 & .052 & & & & \\
\hline & Flock size & 6.79 & 1 & .009 & & & & \\
\hline & Stimulus: Order & 14.22 & 4 & .007 & & & & \\
\hline & Stimulus: Mount exemplar & 0.98 & 1 & .322 & & & & \\
\hline
\end{tabular}


Carlson et al. 242

\begin{tabular}{lllrl} 
& Stimulus: No. crested tits & 27.93 & 2 & $<.001$ \\
& Stimulus: Blue tits present & 10.32 & 2 & .006 \\
Stimulus: Great tits present & 8.42 & 2 & .015 \\
Stimulus: Flock size & 0.45 & 2 & .800 \\
Propensity to use & Intercept & 0.39 & 1 & .531 \\
Tonal calls (1) & Stimulus & 0.67 & 2 & .714 \\
Order & 0.52 & 2 & .771 \\
Mount exemplar & 4.85 & 1 & .028 \\
No. crested tits & 0.12 & 1 & .729 \\
Blue tits present & 0.41 & 1 & .521 \\
Great tits present & 1.78 & 1 & .182 \\
Flock size & 0.03 & 1 & .867 \\
Stimulus: Order & 2.86 & 4 & .582 \\
Stimulus: Mount exemplar & 0.08 & 1 & .784 \\
Stimulus: No. crested tits & 0.35 & 2 & .840 \\
Stimulus: Blue tits present & 0.17 & 2 & .921 \\
Stimulus: Great tits present & 0.78 & 2 & .676 \\
Stimulus: Flock size & 0.07 & 2 & .966 \\
\hline
\end{tabular}




\section{Table A5}

Test Results for Generalized and Linear Mixed Models Testing for Predator Type, Group Size (Conspecific and Flock Size) and Composition (Presence of Blue, Great, and Coal Tits) on Ways of Encoding Information about Predator Threat for Marsh Tits. § Indicates the Model Residuals were not Normally Distributed, L and Bc Indicate that Data was $\log (L)$ or Box-Cox $(B c)$ Transformed if Residuals were not Normal for Linear Mixed Models. Bonferroni Corrected P-Values Based on the Number of Models are .017.

\begin{tabular}{|c|c|c|c|c|c|c|c|c|c|c|c|c|}
\hline $\begin{array}{l}\text { Encoding Method } \\
\text { Call/element type }\end{array}$ & Factors & $\chi^{2}$ & df & $p$ & $\begin{array}{l}\text { Call/element type } \\
\text { Factors }\end{array}$ & $\chi^{2}$ & df & $p$ & $\begin{array}{l}\text { Call/element type } \\
\text { Factors }\end{array}$ & $\chi^{2}$ & df & $p$ \\
\hline \multirow[t]{10}{*}{$\begin{array}{l}\text { Number of } \\
\text { Dä/D elements }\end{array}$} & Intercept & 0.18 & 1 & .669 & & & & & & & & \\
\hline & Stimulus & 2.09 & 2 & .352 & & & & & & & & \\
\hline & Order & 2.85 & 2 & .240 & & & & & & & & \\
\hline & Mount exemplar & 0.43 & 1 & .514 & & & & & & & & \\
\hline & No. marsh tits & 6.65 & 1 & $.010+$ & & & & & & & & \\
\hline & Flock size & 0.09 & 1 & .768 & & & & & & & & \\
\hline & Stimulus: Order & 10.78 & 3 & .013 & & & & & & & & \\
\hline & Stimulus: Mount exemplar & & 0 & & & & & & & & & \\
\hline & Stimulus: No. marsh tits & & 0 & & & & & & & & & \\
\hline & Stimulus: Flock size & 0.03 & 2 & .983 & & & & & & & & \\
\hline \multirow[t]{11}{*}{$\begin{array}{l}\text { Proportion of } \\
\text { Full tonal elements }(1, \S)\end{array}$} & Intercept & 5.00 & 1 & .025 & & & & & & & & \\
\hline & Stimulus & 0.19 & 2 & .910 & & & & & & & & \\
\hline & Order & 0.63 & 2 & .728 & & & & & & & & \\
\hline & Mount exemplar & 3.93 & 1 & .048 & & & & & & & & \\
\hline & No. marsh tits & 7.55 & 1 & .006 & & & & & & & & \\
\hline & Flock size & 0.37 & 1 & .541 & & & & & & & & \\
\hline & Stimulus: Order & 8.12 & 4 & .087 & & & & & & & & \\
\hline & Stimulus: Mount exemplar & & 0 & & & & & & & & & \\
\hline & Stimulus: No. marsh tits & 5.11 & 1 & .024 & & & & & & & & \\
\hline & Stimulus: Flock size & 6.29 & 2 & .043 & & & & & & & & \\
\hline & & & & & Peak tonal elements & & & & Ptew calls & & & \\
\hline \multirow{3}{*}{$\begin{array}{l}\text { Propensity to use } \\
\text { All tonal elements } \\
\text { Table A5 cont. }\end{array}$} & Intercept & 0.31 & 1 & .578 & Intercept & 0.67 & 1 & .415 & Intercept & 0.31 & 1 & .578 \\
\hline & & & & & & & & & & & & \\
\hline & Stimulus & 2.26 & 2 & .323 & Stimulus & 0.53 & 2 & .768 & Stimulus & 2.26 & 2 & .323 \\
\hline
\end{tabular}


Carlson et al. 244

\begin{tabular}{|c|c|c|c|c|c|c|c|c|c|c|c|}
\hline Order & 6.00 & 2 & .050 & Order & 0.25 & 2 & .882 & Order & 6.00 & 2 & .050 \\
\hline Mount exemplar & 0.00 & 1 & 1.00 & Mount exemplar & 1.08 & 1 & .299 & Mount exemplar & 0.00 & 1 & 1.000 \\
\hline No. marsh tits & 0.03 & 1 & .853 & No. marsh tits & 2.81 & 1 & .094 & No. marsh tits & 0.03 & 1 & .853 \\
\hline Flock size & 0.23 & 1 & .634 & Flock size & 1.85 & 1 & .174 & Flock size & 0.23 & 1 & .634 \\
\hline Stimulus: Order & 3.53 & 4 & .473 & Stimulus: Order & 2.37 & 3 & .499 & Stimulus: Order & 3.53 & 4 & .473 \\
\hline Stimulus: Mount exemplar & & 0 & & Stimulus: Mount exemplar & & 0 & & Stimulus: Mount exemplar & & 0 & \\
\hline Stimulus: No. marsh tits & 0.02 & 1 & .894 & Stimulus: No. marsh tits & 0.01 & 1 & .933 & Stimulus: No. marsh tits & 0.02 & 1 & .894 \\
\hline Stimulus: Flock size & 0.16 & 2 & .922 & Stimulus: Flock size & 0.55 & 2 & .758 & Stimulus: Flock size & 0.16 & 2 & .922 \\
\hline
\end{tabular}




\section{Table A6}

Test Results for Generalized and Linear Mixed Models Testing for Predator Type, Group Size (Conspecific and Flock Size) and Composition (Presence of Blue, Great, and Coal Tits) on Ways of Encoding Information about Predator Threat for Willow Tits. \$ Indicates the Model Residuals were not Normally Distributed, L and Bc Indicate that Data was $\log (L)$ or Box-Cox $(B c)$ Transformed if Residuals were not Normal for Linear Mixed Models. Bonferroni Corrected P-Values Based on the Number of Models are .010.

\begin{tabular}{|c|c|c|c|c|c|c|c|c|}
\hline $\begin{array}{l}\text { Encoding Method } \\
\text { Call/element type }\end{array}$ & Factors & $\chi^{2}$ & df & $p$ & $\begin{array}{l}\text { Call/element type } \\
\text { Factors }\end{array}$ & $\chi^{2}$ & df & $p$ \\
\hline & & & & & Call & & & \\
\hline \multirow{11}{*}{$\begin{array}{l}\text { Propensity to use } \\
\text { Rate }\end{array}$} & Intercept & 0.81 & 1 & .367 & Intercept & 0.41 & 1 & .523 \\
\hline & Stimulus & 2.57 & 2 & .276 & Stimulus & 3.31 & 2 & .191 \\
\hline & Order & 0.52 & 2 & .771 & Order & 0.54 & 2 & .764 \\
\hline & Mount exemplar & 0.19 & 1 & .661 & Mount exemplar & 0.25 & 1 & .618 \\
\hline & No. willow tits & 0.69 & 1 & .408 & No. willow tits & 0.56 & 1 & .454 \\
\hline & Flock size & 0.34 & 1 & .558 & Flock size & 0.02 & 1 & .886 \\
\hline & Stimulus: Order & 0.33 & 2 & .846 & Stimulus: Order & 0.50 & 2 & .779 \\
\hline & Stimulus: Mount exemplar & 4.00 & 1 & .045 & Stimulus: Mount exemplar & 4.85 & 1 & .028 \\
\hline & Stimulus: No. willow tits & 2.42 & 2 & .298 & Stimulus: No. willow tits & 1.14 & 2 & .566 \\
\hline & Stimulus: Flock size & 9.82 & 2 & .007 & Stimulus: Flock size & 10.95 & 2 & .004 \\
\hline & & & & & Si intro elements (l) & & & \\
\hline \multirow[t]{10}{*}{$\begin{array}{l}\text { Number of } \\
\text { Total elements }(1, \S)\end{array}$} & Intercept & 5.32 & 1 & .021 & Intercept & 4.07 & 1 & .044 \\
\hline & Stimulus & 15.12 & 2 & .001 & Stimulus & 2.74 & 2 & .254 \\
\hline & Order & 5.67 & 2 & .059 & Order & 6.86 & 2 & .032 \\
\hline & Mount exemplar & 0.03 & 1 & .861 & Mount exemplar & 0.03 & 1 & .874 \\
\hline & No. willow tits & 0.02 & 1 & .897 & No. willow tits & 0.37 & 1 & .544 \\
\hline & Flock size & 1.05 & 1 & .305 & Flock size & 0.06 & 1 & .810 \\
\hline & Stimulus: Order & 10.47 & 2 & .005 & Stimulus: Order & 3.19 & 2 & .203 \\
\hline & Stimulus: Mount exemplar & 0.36 & 1 & .549 & Stimulus: Mount exemplar & 0.38 & 1 & .538 \\
\hline & Stimulus: No. willow tits & 7.17 & 2 & .028 & Stimulus: No. willow tits & 2.60 & 1 & .107 \\
\hline & Stimulus: Flock size & 0.63 & 1 & .429 & Stimulus: Flock size & 0.02 & 1 & .884 \\
\hline \multirow[t]{2}{*}{$\begin{array}{l}\text { Propensity to use } \\
\text { Zizi calls (1) }\end{array}$} & Intercept & 119.08 & 1 & $<.001$ & & & & \\
\hline & Stimulus & 70.93 & 2 & $<.001$ & & & & \\
\hline
\end{tabular}


Carlson et al. 246

Order

Mount exemplar

No. willow tits

Flock size

Stimulus: Order

Stimulus: Mount exemplar

Stimulus: No. willow tits

Stimulus: Flock size $\begin{array}{lll}1.95 & 1 & .163\end{array}$

$\begin{array}{lll}8.42 & 1 & .004\end{array}$

$98.00 \quad 1<.001$

$21.212<.001$

$25.36 \quad 1<.001$

$\begin{array}{lll}9.12 & 2 & .010\end{array}$

$94.71<.001$

